\title{
Surveying fake news: Assessing university faculty's fragmented definition of fake news and its impact on teaching critical thinking
}

\author{
Andrew P. Weiss * (D), Ahmed Alwan, Eric P. Garcia and Julieta Garcia
}

* Correspondence: andrew.weiss@ csun.edu

California State University, Northridge, 427 Oviatt Library, 18111 Nordhoff St., Northridge, CA 91330-8328, USA

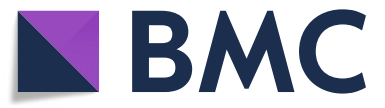

\section{Main text}

The mainstream U.S. news media with their First Amendment protections, universities with their educational credentials and missions, and libraries with their sociallymandated charges to serve their communities exist and function at the forefront of knowledge creation and dissemination. As such, they bear the brunt of the responsibility for resisting information pathologies such as fake news, information overload, educational failure, the proliferation of lies, propaganda, misinformation, disinformation, and weaponized falsity. As far back as George Orwell in the 1940s people have been warned of the pernicious impact of politicized language and its ability to be rendered ineffective through vagueness and unclear thinking (Orwell 1946/2011). Universities have taken approaches to combat these modes of thinking through education that seeks to instill critical faculties in their students. Critical thinking and information literacy have become core values in universities for combating the problem of fallacious,

(c) The Author(s). 2020 Open Access This article is distributed under the terms of the Creative Commons Attribution 4.0 International License (http://creativecommons.org/licenses/by/4.0/), which permits unrestricted use, distribution, and reproduction in any medium, provided you give appropriate credit to the original author(s) and the source, provide a link to the Creative Commons license, and indicate if changes were made. 
lazy and erroneous thinking (Schuster 2007). Most universities take at face value the necessity to teach their students not only factual knowledge but also the capabilities of thinking for themselves.

Yet, despite the best efforts of universities, libraries and the news media, these problems have proliferated, exacerbated by the development of information technologies applied in unforeseen ways that both connect people in positive ways (through social media and the like) and manipulate and nudge people in negative ways (through surveillance, tracking, and targeted advertisement). Indeed, some have come to define the current era as one of 'post-truth' (Oxford Dictionary 2016), or 'post-fact' (Mihailidis and Viotty 2017), asserting that the lack of provenance created by the digital environment combined with the limited-and some might even say stunted-information seeking habits of Internet users. The impact of nudging and other technological manipulations on Internet users has also obscured the availability of reliable, factual, and relevant information. The irony we must note is that the more information people have access to, and the higher the resulting affective load on their search behavior, the less easily they are able to consistently find reliable and relevant resources (Nahl 2004). One of the results of a society wrangling with the implications of this post-truth culture is the development of the phenomenon of fake news, which has proliferated as the means to distribute information has reached a level of near-instant universality.

One of the essential questions that comes out of this research inquiry into fake news is how teaching faculty (i.e. in contrast to non-teaching faculty such as academic librarians, counselors, and coaches) at universities are actually thinking about the concept and addressing it in their classrooms. The overarching goal of this study is to determine how teaching faculty raise the topic of fake news in their research or disciplines, and in their teaching. Taking a wider perspective, the topic of teaching fake news also touches upon the role of critical thinking in higher education and how faculty develop students into informed citizens.

For the purposes of this paper, we are specifically focusing on whether fake news has greater or lesser impact on certain academic disciplines in comparison to others. How, in other words, does fake news impact faculty? How is it defined by them? Does a faculty member's college or departmental ties impact their views of it? Does their age, rank, or gender have an impact on how they view fake news? All of these issues are addressed in the research findings below.

\section{Literature review}

\section{The origins of fake news}

McNair (2018) examines the media's role in the spread of fake news, starting from the late 1800s and 1920s, providing historical examples of the term's use and development over time. However, researchers have also examined similar phenomena extensively in such areas as psychology, sociology, political science and information science. Balmas (2014) examines how fake news affects feelings of inefficacy, alienation, and cynicism. Allcott and Gentzkow (2017) look at the impact of fake news on the 2016 presidential election. McGivney et al. (2017) examine how information literacy can be employed to help empower students. But examining university faculty attitudes toward fake news, as we will see, is not currently well-documented. 


\section{Proposed definitions of fake news}

The origins of fake news run deeper than the relatively recent coinage of the term would suggest. One might argue that the problem of fake news is, in actuality, an old one that has existed under a number of different names and conceptual frameworks for hundreds if not thousands of years. Before we can fully understand the concept of fake news in its current usage, we will need to examine some of the overarching concepts and ideas that comprise it. Fake news itself is an amalgam of long-standing approaches and strategies taken to delegitimize information itself. We can therefore examine fake news from a number of different essential perspectives, including its role as a player in political propaganda and disinformation; its role within rumor and the spread of misinformation; and, finally, its role in parody, satire and a term defined as 'political kayfabe'.

\section{Fake news as a result of information overload and "the principle of least effort"}

Information overload is an important aspect of information theory as it represents a breakdown, or systemic information pathology in the mechanism of information sharing. Though the current technology has flooded people with information, and there are contemporary calls for innovative ways to make it stop, Blair (2010) suggests that information overload has been in existence for as long as the written word has been around. Though the concept is complex as Eppler and Mengis (2004) describe it, there are clear impacts on people's decision-making abilities. Essentially people reach a 'point of noreturn' where their ability to process information becomes less efficient and decisionmaking becomes less-accurate. At some point, as Good (2017) demonstrates, people either choose what they know or they choose nothing, essentially becoming 'aliterate'. An online environment of information glut and overload can contribute to people's choice burnout.

Similarly, the "Principle of Least Effort" is a well-documented phenomenon in Library and Information Science literature. People searching for information prefer resources that are easily accessed regardless of their intellectual value or relevance. Zipf (1949) As a result, fake news can proliferate whenever people are unwilling or unable to take the time to look into the facts. It is an ongoing problem since it must take into account individual's varying levels of tolerance for ambiguity and their ability to accept and parse different viewpoints, while also using little energy to do so. At some point, people may accept fake news as reality by virtue of their sheer exhaustion in the face of information glut. The results are predictable: Balmas (2014) finds that the more people are exposed to fake news, and the less they are exposed to real news as a result, the more susceptible they are to fake news' deleterious effects.

\section{Fake news as a result of poisoned public discourse, logical fallacies and overconfidence}

In addition to the problem of information overload preventing people from making rational choices, public discourse is often poisoned by the deliberate use of logical fallacies that people are unable or unwilling to identify. Psychology and social science abounds with research into why people come to believe the unbelievable, and why they refuse to change their minds in the face of factual evidence that contradicts their belief. Uscinski and Parent (2014) report that in experiments "inducing anxiety or loss of control triggers respondents to see nonexistent patterns and evoke conspiratorial 
explanations" and that in the real world "there is evidence that disasters (e.g., earthquakes) and other high-stress situations (e.g., job uncertainty) prompt people to concoct, embrace, and repeat conspiracy theories." (p. 11) Importantly, conspiracy is seen as a continuum in a "conspiracy dimension", within which all of us fall somewhere between extremely naive (e.g. there are no conspiracies; all is true) and extremely cynical (e.g. all is a conspiracy; everything is a lie).

Additionally, rhetorical and logical fallacies are regularly employed in political discourse for the purpose of persuading voters. Yet these fallacies reveal blatant untruths that people persist in believing, regardless of the evidence. Blassnig, et al. (2018) examine the use of fallacies in right wing populist campaigns, and find that "fallacies are used in more than a third of all analyzed texts and overwhelmingly co-occur with populist key messages" (Blassnig, et al. 2018) Zurloni and Annoli (2010) find that numerous information fallacies "are strategically used by politicians in order to put forward coherent and strong positions." What this suggests is that the poisoning of public debate contributes to the factors allowing fake news to proliferate. The political discourse, already flooded with disinformation by politicians, provides fertile ground for fake news to grow. By repeating fallacies enough times, and reinforcing them through fake news, faulty information is able to persist. Chatman (1996) proposes "information poverty" as a possible cause of some related negative information behaviors in users, especially with self-protective behavior that tries to hide real feelings as well as a general mistrust in others to provide information.

Additionally, the Kruger-Dunning effect suggests that people can habitually overestimate their abilities and their knowledge of a subject, leading to failed outcomes or overall incompetency. In a recent study on the people's acceptance of GeneticallyModified Foods by Fernbach, et al. (2019), it is noted that "Extreme opponents know the least, but think they know the most." Extreme views in this case stem from people thinking they know more about a complex topic than they really do. False stories, rumors, and fake news rooted in extremist thinking can spread as a result of this welldocumented psychological phenomenon.

\section{Fake news as context-independent in a "Post-truth" society}

Another factor contributes to the widespread adoption of fake news. The Internet, with its uncanny ability to copy everything within it and spread it around to anyone at any time, has broken the concept of provenance. Factual information depends entirely upon the provenance from which it was derived. Without this tether to an unshifting reality, authority becomes displaced, diffused, and circumvented. As Clarke (2017) writes, the "paradox of the Information Age is that while we have access to many more and diverse information sources, it is getting harder to determine the origin and authenticity of information, to distinguish fact from opinion and truth from lies." (Clarke, 2017). The problem falls partly, then, on the stewards of information (i.e. libraries and Internet providers, information management companies, etc.) to provide a sound structure for the sharing of information, especially as "the sociology of knowledge understands human reality as socially constructed reality" (Berger and Luckmann 1966). Fake news proliferates in an environment where reality is no longer tethered to clear authoritative contexts. The concept of post-truth seems to convey this sense that the mechanism for 
verifying something as truthful has been both superseded as well as circumvented by digital information technologies.

\section{Fake news as propaganda/disinformation}

One of the easiest ways to conceptualize fake news is as a method of propaganda. Disinformation, which one could argue is synonymous with propaganda, is defined as the willful distortion of factual information to promote a specific end result or to sow confusion about a perceived counter-viewpoint. Hintz (1940), quoting Calvin Coolidge in his 1940 article on libraries and propaganda, writes,

Propaganda seeks to present part of the facts, to distort their relations, and to prove conclusions which could not be drawn from a complete and candid survey of all the facts. Of real education and real information we cannot get too much; but of propaganda we cannot have too little. (p. 171).

This definition is not dissimilar from many contemporary conceptions of fake news. Brennen (2017) writes, "Fake news is made-up news, manipulated to look like credible journalistic reports that are designed to deceive us" (p. 180). This describes the most common approach to fake news, which is to distort factual information to reach wildly different ends than those suggested by a good-faith and truthful reading. Importantly, though, as Hintz (1940) points out so clearly and presciently, there is a clear distinction between education and propaganda, suggesting that there are approaches to neutralizing the effects of this distortion of truth through learning.

Taylor (2003) suggests in Munitions of the mind: A history of propaganda, that propaganda and its tools have been around for a long time, starting with essentially the organization of early civilizations. What has changed significantly, however, is not the message or the motivations for distorting the message, but the medium across which it is transmitted. As Brian Schafer for the Alliance for Securing Democracy demonstrates in summary to the Alliance's yearlong observation of Russian disinformation campaigns, the Internet is lightning-quick in comparison to traditional print and television media, taking days and weeks instead of years to circulate false stories (Schafer 2018).

However, to focus on fake news as merely an aspect of propaganda is to overstate the case somewhat, as the term is mainly associated nowadays with the concept of war and war-time efforts at changing the hearts and minds of people at home and abroad. But the proliferation of fake news straddles both the concept of information wars and the general politicization of language and fact. In this sense, fake news as a form of propaganda can only partially explain the overall phenomenon.

\section{Fake news as rumor, misinformation, and conspiracy theory}

While disinformation and propaganda are a willful distortion or misconstruing of fact for the sake of political or physical gain in both times of peace and during warfare, misinformation and rumor are unwitting distortions arising from ignorance and the repeating of erroneous information. This also might fall under the rubric of fake news. Someone who truly believes that the earth is flat may come to create a video or write an article that utilizes this erroneous information. This false information might actually be considered truthful to some. Yet, even in cases where a conspiracy theory can be easily debunked with factual information, people nonetheless persist in believing the 
conspiracy. Some of this is partisan-based signaling, "calling cards" to distinguish between their co-partisans and non-partisans (Smallpage et al. 2017); some of this is sheer mistrust of power held by organizations (Kramer 1999). But, like the problem of conflating fake news with propaganda, it would be a mistake to merely judge fake news by its function as a vehicle for unwittingly spreading false information or emotion-based opinions.

\section{Fake news as parody, satire, and political kayfabe}

Fake news can also be seen as part of the wider phenomenon of parodic news stories, as it tends to imitate the form of legitimate news to fool the readers. Parody performs a distinct function in literature as a way to ridicule genres and literary conventions while also giving homage to the source material. Satire similarly mimics source material, but with the aim to shine the light on people and present them and their behaviors in a harsher light. Saturday Night Live's (SNL) Weekend Update is perhaps the best example of this conflation of both parody and satire working in tandem, allowing the creators to entertain viewers with the familiar setting of a TV news desk, while also conveying commentary and jokes that skewer public figures. Yet no one would reasonably assert that SNL is attempting to spread fake news through its show. Its over-thetop approach and clear comedic context provide viewers with the cues to understand that these are jokes. Golbeck et al. (2018) point out that the differences between satire and fake news are often difficult to discern, as consumers may not see the context or understand the joke. That line gets blurred easily, it is true, but the key is that the loss of context - especially on the Internet - sometimes accounts for this confusion of satire and false news stories. As both approaches are necessarily copying and mimicking legitimate source materials, models, and conventions, distinguishing between satire and fake news is as much about discerning the intentions of the creators as it is the actual format.

There is more to it, though, than mistaken contexts, misunderstood jokes and mimicked genre conventions. In this regard, we turn to Stodden and Hansen (2016) and their conception of politics as something out of professional wrestling stagecraft, kayfabe, which they define as "the accepted substitution of reality and willing suspension of disbelief that allows fans to buy into often fictionalized storylines" (p. 1). This suspension of disbelief, often colloquially known as 'make-believe,' is an accepted aspect of the ultimate goal of entertainment and theatrical catharsis. Political discourse and political campaigns run on similar rituals and pretensions as stagecraft. In other words: political theater.

In that sense, some fake news might also fall under this conception of political kayfabe, where voters or consumers of a fake news story may consider it to be as farfetched as a UFO story in the National Enquirer magazine. But the story provides the reader with an excuse for catharsis, a convenient chance to vent frustrations about political adversaries and exult in their enemies' defeats. This may help to explain why the misstatements that President Donald J. Trump routinely spreads--13,435 false or misleading claims as of October 2019--are acceptable to and even encouraged by his political base (Washington Post 2019). It is not necessarily, then, about the truthfulness of these statements for the spectators and followers. It is instead about the adversarial 
nature of the political stage and the catharsis that comes with it, as the rituals wrapped in staged spectacles are carried out until political rivals are vanquished.

\section{Toward a unified definition of fake news}

Ultimately, though, we argue that fake news needs to be conceptualized as a combination of these various factors. It is far more than Golbeck et al.'s definition of fake news as "information, presented as a news story that is factually incorrect and designed to deceive" (Golbeck et al. 2018, p. 19). While this certainly satisfies a narrow interpretation of the fake news phenomenon, we have also seen that stories in The Onion satirical magazine have ended up being taken seriously. At the same time, those looking to gain from spreading lies through the willful planting of false information from whatever source they may be derived (say Russian disinformation campaigns) can also find that fake news serves other purposes than mere deception, including for the sake of reaping financial profit, gaining online notoriety or attaining personal enjoyment. The debasing of faith in information can also force those targeted by fake news to cede the power of truth in its own right.

What binds both sides of the fake news phenomenon - 'the actors' and 'the actedupon' as we have defined them - is the suspension of disbelief coupled with the spread of false information. The two threads are indelibly intertwined, needing both sides to complete and perpetuate the cycle. However, it is important to note that the suspension of disbelief along with the spread of false information can be both willing and unwilling as well as intended and unintended. This adds to the general confusion and lack of clear understanding of what fake news really is.

It is our assertion, then, that fake news should be defined in broader terms as the phenomenon of information exchange between an actor and acted upon that primarily attempts to invalidate generally-accepted conceptions of truth for the purpose of altering established power structures. There are a couple of points to consider. First, we believe that this attempt to invalidate what is true can be either intentional (as in the case of misinformation/disinformation) or unwitting (as in the case of mistaken beliefs); and, second, affected power structures can be altered either through subverting them or by fortifying them. In other words, fake news is a double-edged sword, capable of helping or harming established power structures while also being applied to both aggressor and victim.

\section{The implications for higher education}

Developing students' critical thinking skills rightfully remains a major goal of American higher education system (Roth 2010). "Many colleges and universities in North America now offer courses specifically designed to enhance their students' abilities to think critically, as part of the general education requirements" (Halpern 1999, p. 70). Advancing these skills fulfills the goal of higher education to develop a responsible citizenry, especially as the amount of information on any given subject is increasing at an exponential rate and specific skills are quickly outdated. In an increasingly complex informationbased society, it is imperative that individuals base their judgments and decisions on accurate evidence (Renaud and Murray 2008). 
From a pedagogical perspective, the development of critical thinking skills is seen as essential in enabling students to engage in purposeful, self-regulatory judgment (BeharHorenstein and Niu 2011). Providing students in higher education with such skills helps them evaluate the arguments of others and their own, resolve conflicts, and come to rational determinations about complex topics or issues (Allegretti and Frederick 1995). It also helps students become aware of the powerful social forces at work in the world which serve to silence and marginalize others, restricting human freedom (Davies and Barnett 2015).

Cooke (2017) argues that critical thinking helps users of information take a proactive approach, allowing them to be selective about what information is acceptable and maintain a necessary skepticism. This emphasis on using critical thinking to thwart the spread of fake news is not new. Kovach and Rosenstiel (2011) exhort readers and listeners to not simply accept what they see and hear, but to constantly question all information presented to them. The cultivation of critical thinking skills, therefore, becomes an essential tool to combat the proliferation of fake news. Armed with critical thinking, students should be able to identify the characteristics of fake news.

However, critical thinking's implementation in higher education varies across disciplines and organizations (Egan, 2019). Tsui (2002) questions whether it can be promoted through instruction. It is also unclear whether critical thinking is too discipline specific, as some assert that instruction can only be effective if embedded within "subject-specific knowledge and skills" (Behar-Horenstein and Niu 2011). While others suggest that critical thinking is merely a general set of skills that must be taught separately (Ennis, 1989). Ultimately, however, the lack of consensus on how to teach critical thinking may likely have an impact on how students interact with information, including how they verify it and come to conceive of and identify fake news.

\section{Libraries and the role of information literacy}

Libraries, which function as collection- development and information-vetting organizations within larger institutions, organizations, or constituencies, are keenly aware of the issue of reliability in sources and the need to tolerate ambiguity when it comes to handling information. S.R. Ranganathan stipulated as far back as the 1930s that libraries exist to provide resources for all people: "Every person his or her book," and "Every book its reader". Along those lines, the American Library Association has developed a hands-off policy regarding all literature, even that which is designed to mislead, stoke hatred, or generally advocate for destructive and counter-productive actions. As they say, somewhat controversially, "There is no 'hate speech' exception to the First Amendment" (American Library Association 2019).

Yet librarians are also uniquely positioned as intermediaries (Vedder and Wachbroit 2003) to mitigate the effects of fake news and are charged in their basic work duties with ensuring, via specific information literacy initiatives-- proposed by Kulthau (1993) and Irving (1985), to name a few -- that the right information is available for the right people at the right time. Cooke (2018) suggests that librarians need to be "called upon to use our information literacy skills to help debunk and decipher fake news ... to help our communities and constituents become critical and savvy information consumers". Batchelor (2017) provides "useful tools for library professionals" in order to promote 
"critical thinking". Yet, aside from Cooke's cogent analysis, and the general assumptions like Batchelor's and others within the profession in research and case studies that librarians can lead the way as information professionals toward an information commons via information literacy skills, very little has been studied by librarians about the direct impact of fake news on non-librarians. In a notable exception, El-Rayess, et al. recently examined students' understanding of fake news, but do not examine university faculty attitudes (El-Rayess, et al., 2018).

\section{Methodology}

In an attempt to address the gap in the literature on how university and college faculty address the topic of fake news within their own research and in the classroom, the researchers developed an empirical study in the form of a survey (Appendix 2). The study received an institutional review board exemption from California State University, Northridge (CSUN), Office of Research and Sponsored Programs in October 2017. The researchers designed and deployed a mixedmethods survey containing both quantitative and qualitative questions, using the online survey tool Survey Monkey. The target population for recruitment was tenured and tenure-track teaching faculty as well as faculty on term contracts, such as lecturers and adjunct faculty, currently employed at CSUN. This population was selected on the premise that educators, especially in higher education, may function as a frontline on the topic of fake news, teaching students the critical thinking skills necessary for being ethical users and producers of information.

Although fake news has garnered a significant amount of public attention since the 2016 U.S. presidential election, there remains little in the way of literature on how faculty address the issue in their classrooms. Thus, the researchers had to rely on both the literature and their own experiences observing how students interact with information resources in the classroom, when designing the survey instrument. In an effort to yield information-rich cases, the researchers implemented a purposeful sampling methodology to target applicable survey participants. Although purposeful sampling is typically applied in qualitative research (Palinkas et al. 2015), the researchers were confident that this sampling method could be used effectively to identify information-rich responses related to the phenomenon of fake news in academia. As purposeful sampling involves identifying and selecting individuals or groups of individuals that are especially knowledgeable about or experienced with a phenomenon of interest, it was clear that this method would work best with a study in which the target population was clearly identified. Moreover, this method worked well since it allowed the researchers to maximize efficiency and validity in the research process. Although a variety of purposeful sampling designs exist, the researchers gravitated towards similarity between participants and overall homogeneity of the target population. Despite the emphasis on homogeneity, the researchers remain confident that the strategy would allow for an analysis of variation within the population. This would be achieved by identifying similarities and differences in how teaching faculty with particular characteristics and qualities (e.g., discipline, college, department, rank, age, and gender) addressed the topic of fake news within their own research and as educators.

For the survey, the researchers used a variety of question types. Including yes and no, Likert scale, closed-ended, and open-ended questions. For questions using a Likert scale, 
participants were provided with a six-point scale ranging from "very frequently" to "never, " and "strongly disagree" to "strongly agree," with both variations including a "N/A" (not applicable) option. The survey was comprised of 28 questions divided into four distinct sections: Demographics, Personal Views, In the Classroom, and Role of the Library.

- Demographics: In this section, participants were asked personal demographic questions aimed at anonymously assessing age, gender, college, department, and academic rank.

- Personal Views: In this section, participants were asked about their definition of fake news, if and how they interacted with fake news in their personal lives as well as in their research, whether they felt susceptible to the phenomenon, how they vetted information, and where they most frequently encountered fake news.

- In the Classroom: In this section, participants were asked about how they addressed fake news in the classroom, if their students interacted with fake news, where their students encountered fake news, if specific students were more susceptible, how they taught their students about vetting information for credibility, and the tools and specific resources used to do so.

- Role of the Library: In this section, participants were asked about how they did or did not interact with the university's library and librarians to address inform or teach their students about fake news, whether the library offers reliable resources, if the library and librarians offer sufficient support related to fake news and how the library could improve services, tools, or resources related to fake news.

In an attempt to account for the range of variation in a sample population, which can be a real concern with purposeful sampling, the researchers planned to send the survey to all teaching faculty at CSUN. However, the researchers were informed by the director of the CSUN Office of Institutional Research (IR), that this was not feasible due to policies on campus-wide surveys. In light of this, IR provided a random subsample of 400 teaching faculty (i.e., 18.88\% of CSUN faculty). The random sample included an equal number of tenure-track faculty as well as adjuncts and lecturers drawn from 10 colleges on campus. Subsequently it was forwarded to campus IT for deployment with a preamble for the study that also included a link to the survey. Campus IT sent out the formal email to all 400 faculty on January 19, 2018. The survey, entitled "Fake News Faculty Survey," remained open for a period of 4 weeks and was completed by 69 faculty members from a variety of colleges and departments at CSUN.

or this paper, the researchers have selected questions 6, 7, 8, 9, and 11(see Appendix 1) from the section entitled Personal View in an effort to determine specifically the relationships between the selected questions and select demographic data of discipline, college, department, rank, age, and gender. These five questions were selected because they provide the researchers with insight into how faculty at CSUN conceptualize fake news.

\section{Results}

Demographics

Sixty-nine respondents completed the survey. Aside from the demographic questions, all questions were optional. Making these questions optional altered the total number 
of responses for individual questions. Responses from participants who did not proceed to the end of the survey, but still answered select questions, were included in the data analysis.

Figures 1, 2, 3, 4 and 5 demonstrate the breakdown of survey participants by age, gender, college, department, and rank. Out of 69 respondents who completed the question on age (Fig. 1), there was an even distribution between the ages of 35 to 74, with the smallest number selecting under 34 and over 75. In terms of gender identity (Fig. 2), 38 (55.07\%) participants identified as female and 31 (44.93\%) as male. As for the respective colleges of the participants (Fig. 3), the top three colleges represented in the survey were the College of Social and Behavioral Sciences, Health and Human Development, and Education. The majority of departments (Fig. 4) were represented by one or two individuals, aside from the department of Health Sciences, English, and Biology. Lastly, of the 69 participants, 34 (49.28\%) self-identified as lecturers, 18 (26.09\%) as full professors (Fig. 5), 10 (14.49\%) as associate professors, and 7 (10.14\%) as assistant professors.

\section{Qualitative responses}

For questions seven and eight, we selected department, college and rank to determine if there was a correlation between these demographics and the coding we developed. The coding system (Appendix 2) utilizes codes and categories to allocate meaning to the descriptive or inferential information compiled in the responses to the two questions. Codes were applied to specific responses using the qualitative analysis software NVivo. The aim of applying the coding was to observe and collect examples of the relevant phenomena and to find commonalities, differences, patterns, and structures between individual responses. The commonalities allowed the researchers to ask questions and compare data to determine what factors may drive specific responses. For the qualitative analysis, there was no intercoder error as the researchers co-developed the coding.

For questions seven and eight, data from specific colleges and departments was at times limited to one or two responses, and in some cases no responses. However, we

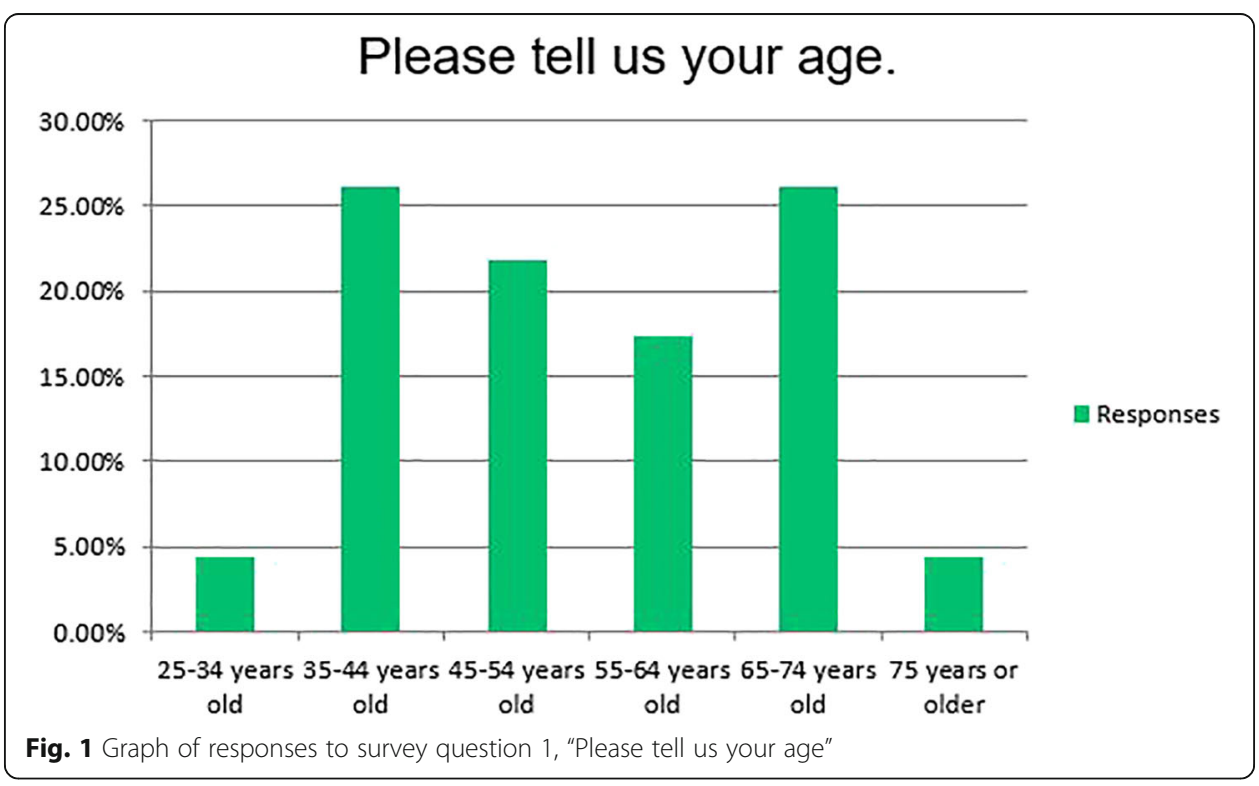




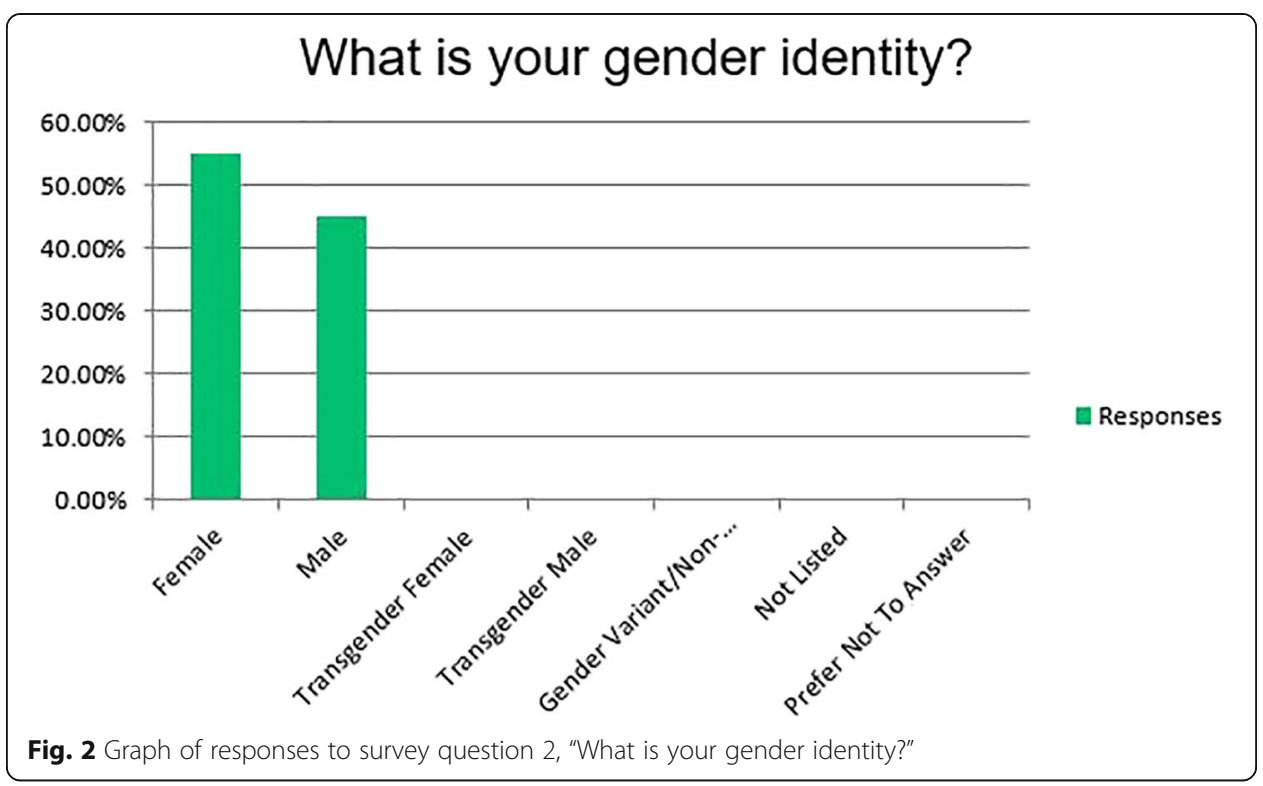

still saw value in including data from questions where the response rate was higher than 5\% (approximately three to four respondents), as this can provide insight into perspectives and attitudes held by faculty about fake news. Maxwell (2013) and Patton (2002) are clear that a small number of participants is appropriate for qualitative studies. Furthermore, Ritchie et al. (2003) note that larger samples in qualitative studies do not necessarily render richer data.

\section{Q.7 department}

In total, 33 out of 58 departments were represented. The four departments with the highest number of participants were Biology (8.7\%), English (8.7), Health Sciences (8.7\%) and Political Science (5.8\%). Only departments that had a response rate higher than $5 \%$ were analyzed. Responses to question seven demonstrate that faculty appear to

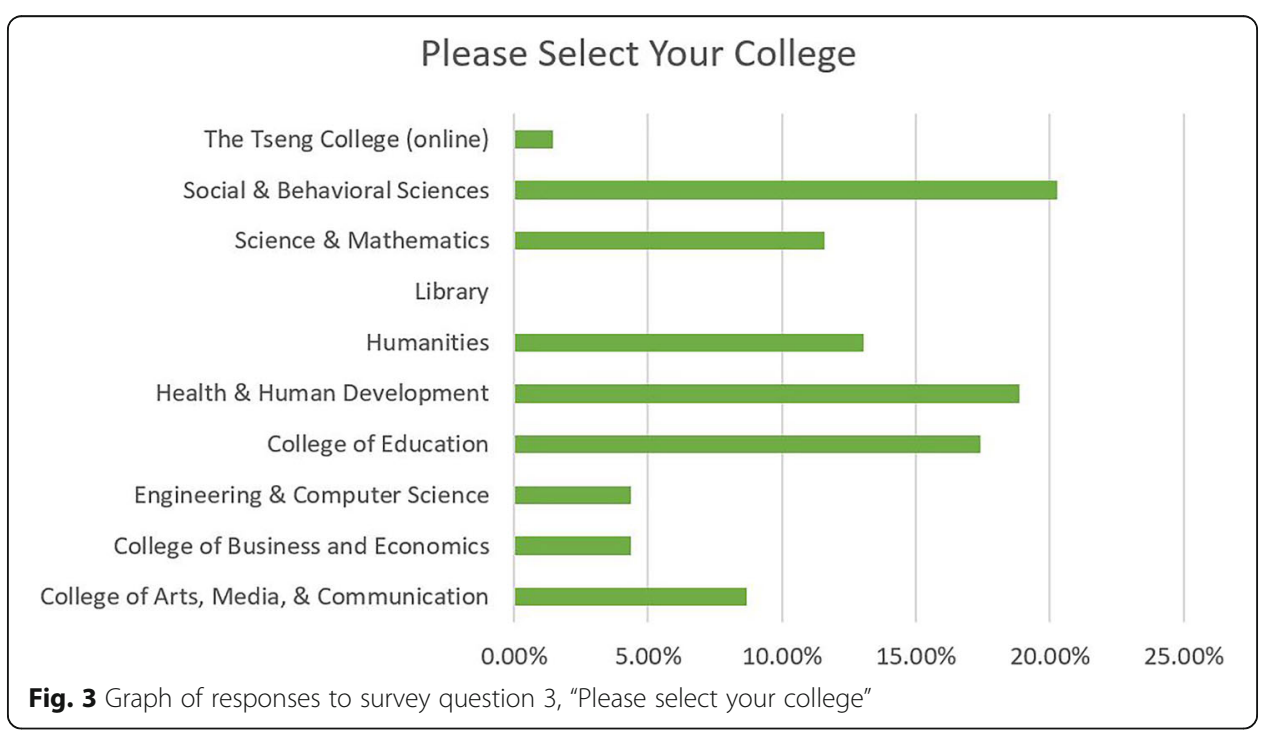




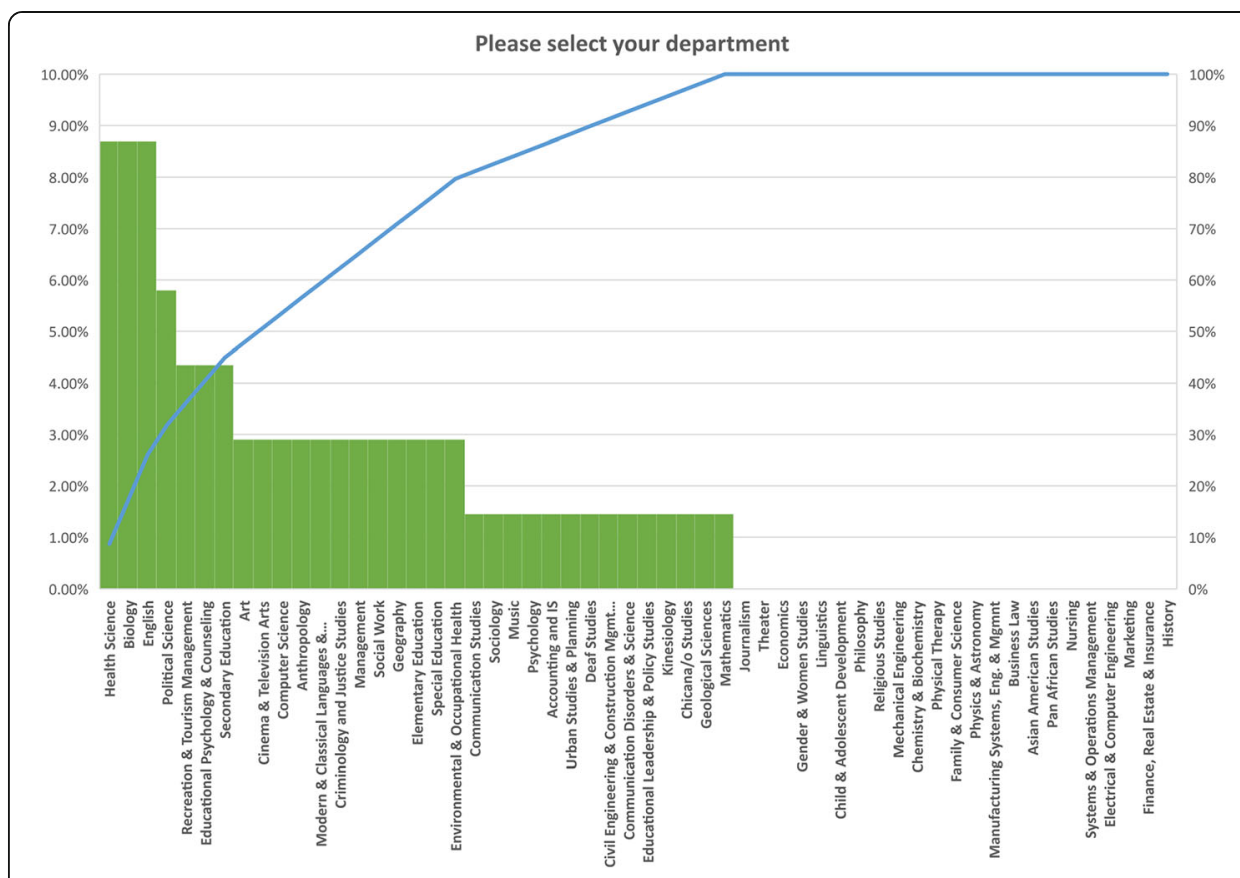

Fig. 4 Graph of responses to survey question 4, "Please select your department"

have different views on the concept of the 'acted upon', specifically as readers or users of information. Departments seem to have differing views on how information is consumed and what makes for an informed reader.

The English Department is the most concerned with the 'acted upon' followed by the motivation of the 'actors'. These faculty focus on the receivers of fake news and the 'motivation' behind the creation of fake news. The 'means of dissemination' does not appear to be essential to their definition of fake news. This is surprising, as we would have assumed that a department that focuses on text and

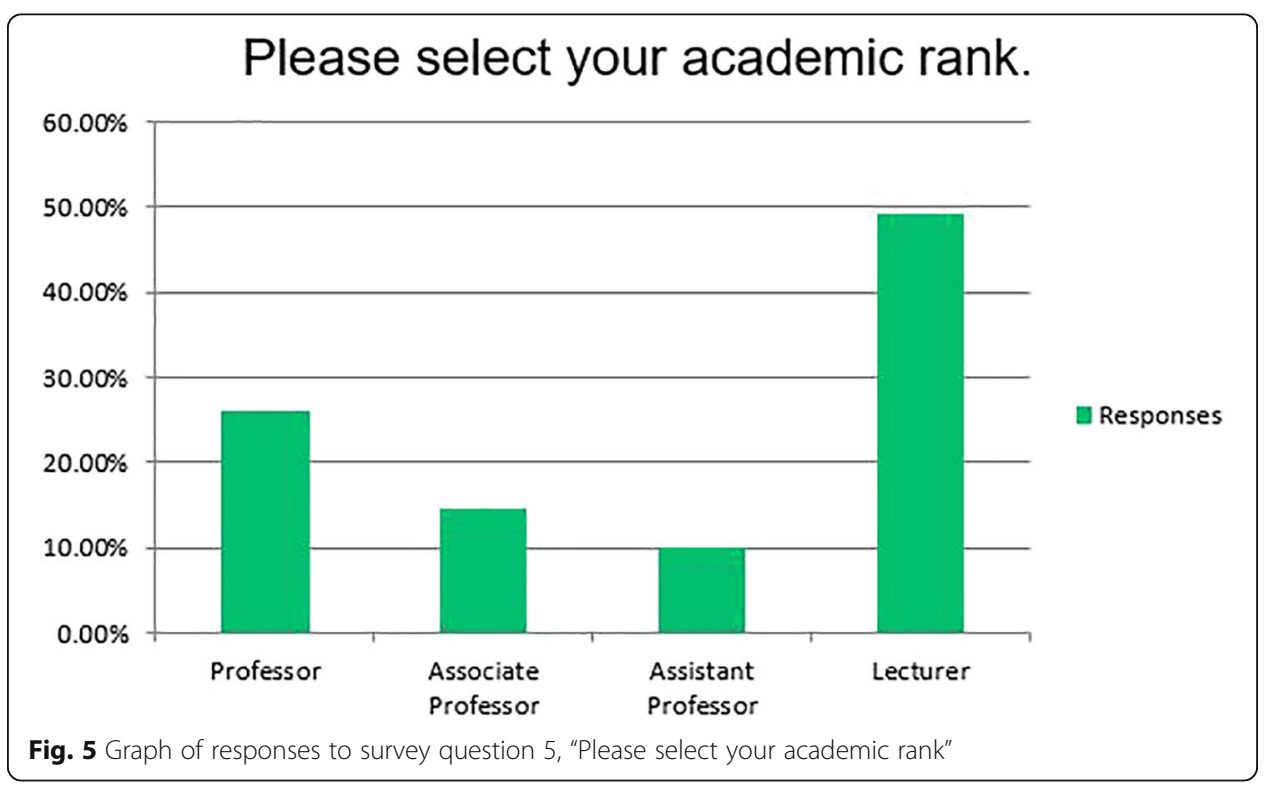


delivery would be more concerned with the 'content type' and the 'means of dissemination'.

The Political Science Department is the most concerned with the 'actors', that is the creators or generators of content and the operators of power. This department is minimally concerned with the 'means of dissemination' (i.e., social media) and not at all with those consuming it (i.e., the 'acted upon'). The focus is on people and power.

The Biology Department was the least concerned with the 'actors' and 'motivation'. However, this department was highly concerned with the 'acted upon' and the 'means of dissemination'.

The Health Sciences Department was concerned with the 'means of dissemination' and the 'content type'. The faculty in this department were generally concerned with how health-related information reaches the wider public. However, this department did not mention the 'acted upon', despite ongoing public health issues that impact people directly, such as vaccines and gun control. It is surmised that Health Sciences faculty are more interested in how information is controlled and how public health narratives are constructed. For these faculty, the responsibility for fake news may not lie with the audience. It is instead the creators' and the disseminators' responsibility to ensure that accurate information is released.

\section{Q.7 college}

Nine of the 10 colleges at CSUN participated in the survey. Only the colleges that had a response rate higher than $5 \%$ were analyzed. As a result, the following four colleges were not examined: Library, School of Business, College of Engineering \& Computer Science, and Tseng College (continuing education).

Faculty responses in the College of Education are not at all concerned with the 'acted upon' and fake news. The emphasis is instead on the 'actor', the 'means of dissemination', and the motivation.

Faculty responses in the College of Social and Behavioral Sciences are similarly not concerned with the 'acted upon'. The 'actors' and the content type are their primary concern. The motivation behind fake news is not as concerning to faculty in this college.

Faculty responses in the College of Arts Media and Communications seemed to assert the opposite of those in the Colleges of Education and Social and Behavioral Sciences, as their focus seems to be largely on the 'acted upon'. The 'actors' receive very little focus in their responses.

Faculty responses in the College of Humanities focus largely on the 'acted upon' with an even distribution of responses referring to the remaining categories.

Faculty responses in the College of Health and Human Development are largely focused on the role of the 'acted upon', 'means of dissemination', and 'motivation' with a slightly lesser concern for the 'actors' and 'content type'.

Finally, faculty in the College of Science and Mathematics also focus largely on the 'acted upon' with an even distribution for most other categories, though 'motivation' seems to be the least of their concerns. 


\section{Q7. Rank}

In response to question seven, Assistant Professors do not mention the 'actors' or 'motivation' in defining fake news. This is the only group under rank that does not mention 'actors' in any of their responses. The emphasis for this group is solely on the 'acted upon'.

Associate Professors do not identify 'acted upon' in any of their responses when defining fake news. The focus of this group was the 'actors' and their role. 'Content type', 'means', and 'motivation' are each referenced equally, but less frequently than 'actors'.

Full Professors do not mention 'acted upon' in any of their responses. However, Full Professors seem to touch upon all the other categories fairly evenly in their responses.

Finally, in contrast to the tenured/tenure-track faculty members (e.g. Full, Associate, Assistant), lecturers heavily emphasize the 'acted upon' and 'motivation' in their responses. Lecturers appeared to provide the most comprehensive definition of fake news, with their responses touching upon all of the coding categories we developed and applied.

\section{Q8. Department}

The researchers did not conduct analysis on the departmental level for question eight, as it was determined that the information was too granular and would not allow for any meaningful analysis.

\section{Q8. Colleges}

We selected colleges that had a rate of response higher than 5\%. As a result, specific colleges were not represented (University Library, School of Business, College of Engineering \& Computer Science, and Tseng College).

Faculty in the College of Education heavily emphasized the act of 'in depth research' and 'fact checking' as a means by which to determine that something is fake news. The college mentioned the act of comparing sources against each other or 'triangulation' the least.

Faculty in the College of Humanities did not mention 'in depth research' at all as an option for determining what constitutes fake news. Rather, they placed a heavy emphasis on the 'content type' and its origin as well as 'fact checking' as key factors.

Faculty in the College of Arts, Media and Communication did not indicate 'in depth research' as an option for determining what constitutes fake news. A large number of respondents from this College failed to indicate a clear strategy for determining what is fake news. Interestingly, many responses also indicated that 'intuition' also plays a role in the process.

Faculty in the College of Science and Mathematics had responses where the concepts of 'triangulation' and 'in depth research' were heavily emphasized as a means by which to determine if something was fake news. Interestingly, 'intuition' was also reported by a substantial number of participants as a method for vetting. Faculty in this college also seem to have a clear sense of specific methods for vetting information, with very few indicating an unclear strategy for determining what is fake news.

Faculty in the College of Social and Behavioral Sciences are the only ones who did not report using 'intuition' as a means by which to determine if something is fake news. 
In addition, no respondents mentioned 'in depth research' as a means by which to vet information. The focus was largely placed on 'triangulation' as well as 'fact checking' sources to a lesser extent.

Faculty in the College of Health and Human Development had the highest rate of respondents who indicated that 'intuition' plays a role in the process of determining if something is fake news. The faculty also had the highest rate of respondents selecting 'in depth research' as an option as well as participants who did not indicate (non answer) a clear strategy for vetting.

\section{Q8. Rank}

Assistant Professors do not mention the use of 'intuition' and 'in depth research' when attempting to determine if something is fake news. The emphasis for this group of faculty was on 'triangulation'.

Associate Professors do not mention the use of 'in depth research' when attempting to determine if something is fake news. This group instead relies on 'intuition' and, to a lesser extent, 'content type' and 'triangulation'.

Professors do not mention the use of 'in depth research' when attempting to determine if something is fake news. For this group of faculty, the main method of determining if something is fake news was 'triangulation'.

Lecturers are the only group who mentioned 'in depth research'. Notably, every response mentioned 'in depth research' as a means by which to determine if something is fake news. In contrast, none of the other ranks mention 'in depth research' or even 'fact checking' in their responses. Responses from Lecturers encapsulate all of the various methods by which to determine if something is fake news. Lecturers who teach the majority of lower-level courses with junior students may be emphasizing 'in depth research' as the best means to determine if something is fake news.

\section{Quantitative responses}

Question six asked participants whether fake news was important to them. Nearly all the respondents (69.49\%) selected 'strongly agree' or 'agree' (18.64\%), with a few selecting 'strongly disagree' (3.39\%) or 'neutral' (8.47\%). Question nine asked participants whether they considered themselves susceptible to fake news as academics or scholars. A clear majority of participants (67.80\%) selected 'no'. Question 11 asked participants where they typically encountered fake news. A significant number of participants selected 'social media' (93.22\%) with other forms of communication being selected far less frequently (See Fig. 6).

For question 6, 9, and 11, the researchers conducted both a cross-tabulation and chisquare analysis to determine if there was a relationship between these questions and the demographic data regarding age, gender, college, department and rank. To conduct this analysis the researchers used the statistical analysis software package SPSS. For the cross-tabulation analysis the only graphs included below are those where statistical significance was observed. Moreover, no graph for department is included as the information is too granular. 


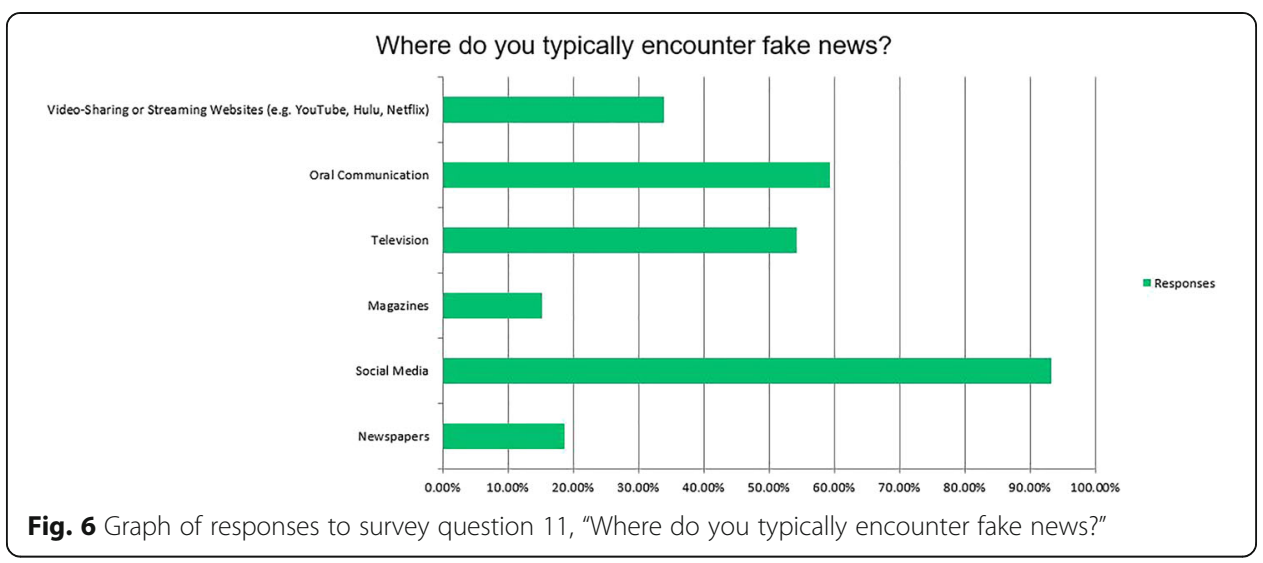

Q.6

The cross-tabulation analysis for age and question 6 (See Fig. 7) determined that all age groups strongly agreed with the notion that fake news was important to them. The chisquare analysis showed no statistical significance.

The cross-tabulation analysis for gender and question 6 (See Fig. 8) determined that both males and females strongly agreed with the notion that fake news was important to them. The chi-square analysis showed no statistical significance.

The cross-tabulation analysis for colleges and question 6 (See Fig. 9) determined that most colleges strongly agreed with the notion that fake news was important to them. However, it was apparent that the majority of respondents from the Mike Curb College of Arts, Media, \& Communication gravitated towards the neutral option when responding to this question. The chi-square analysis showed no statistical significance.

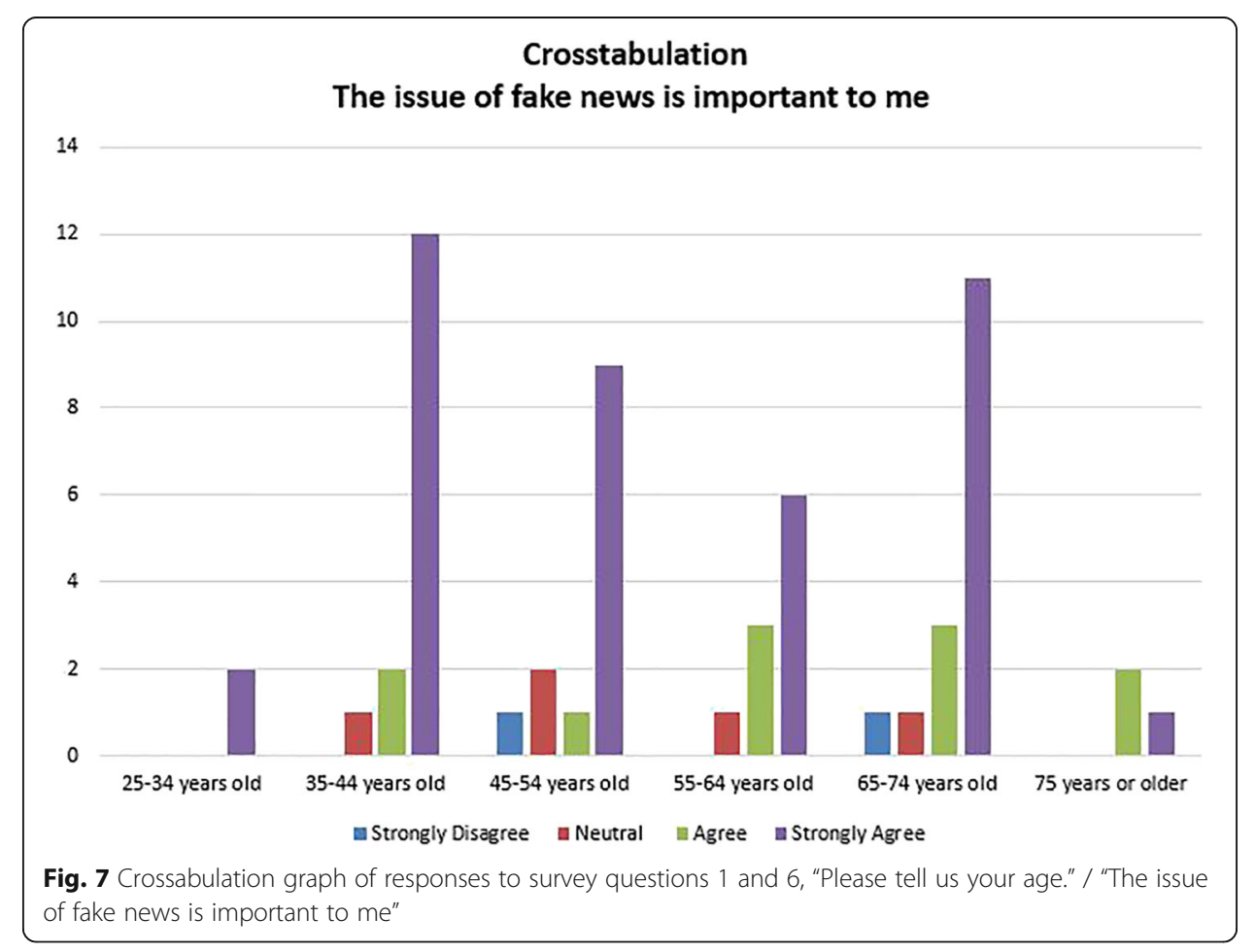




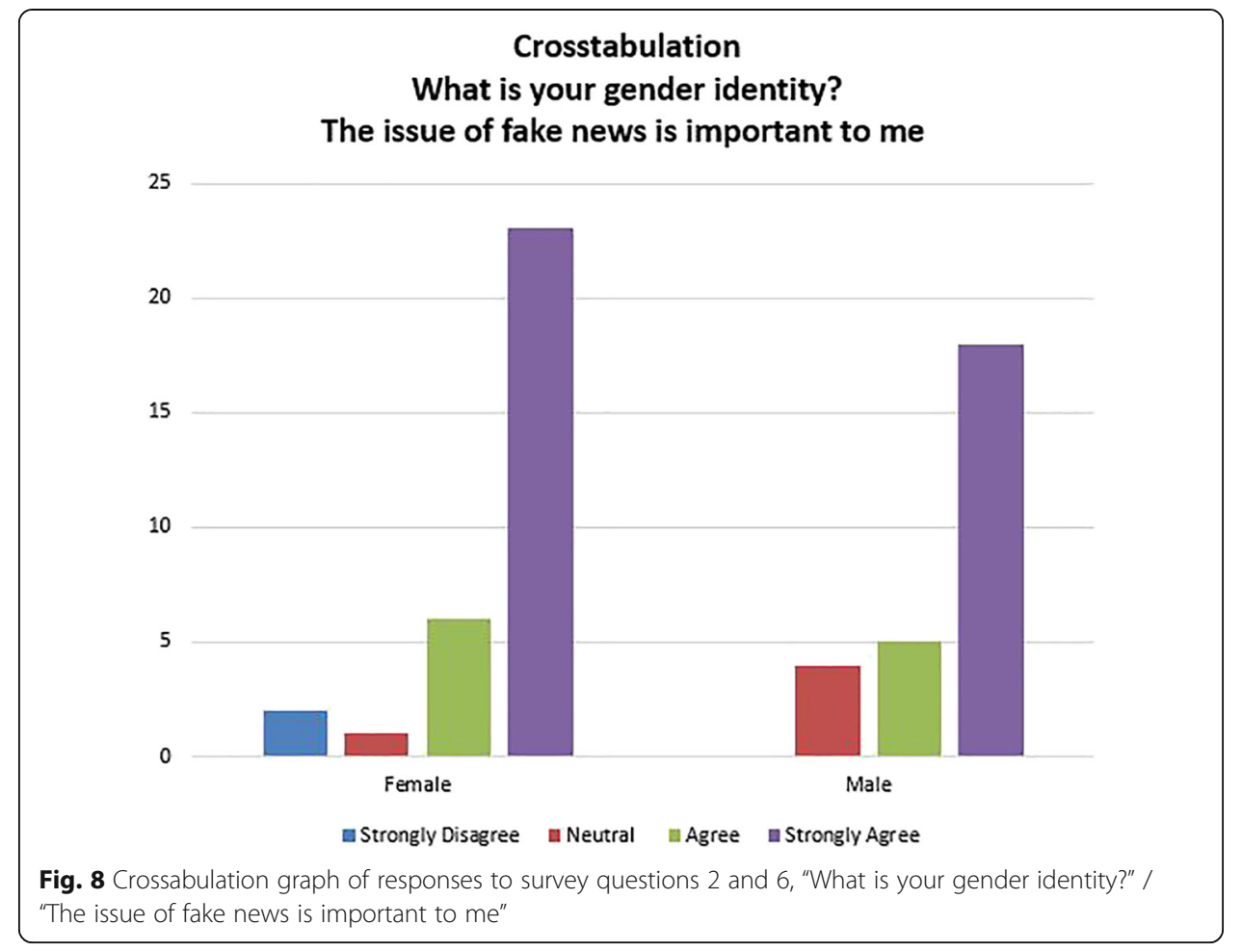

The cross-tabulation analysis for departments and question 6 (See Fig. 10) determined that all departments either agree or strongly agree with the notion that fake news was important to them. The chi-square analysis showed no statistical significance.

The cross-tabulation analysis for rank and question 6 (See Fig. 11) determined that all faculty ranks either agree or strongly agree with the notion that fake news was important to them. It was interesting to note, however, that professors chose the neutral option more than any other rank. The chi-square analysis showed no statistical significance.

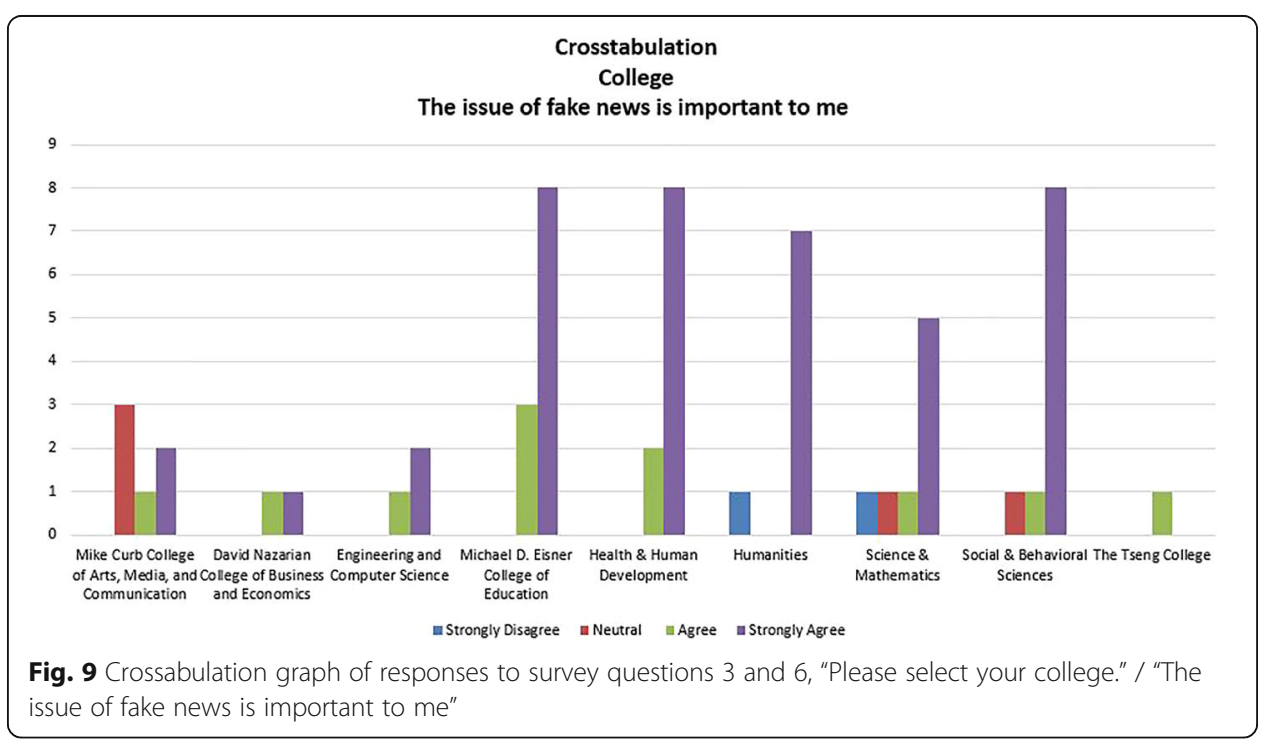




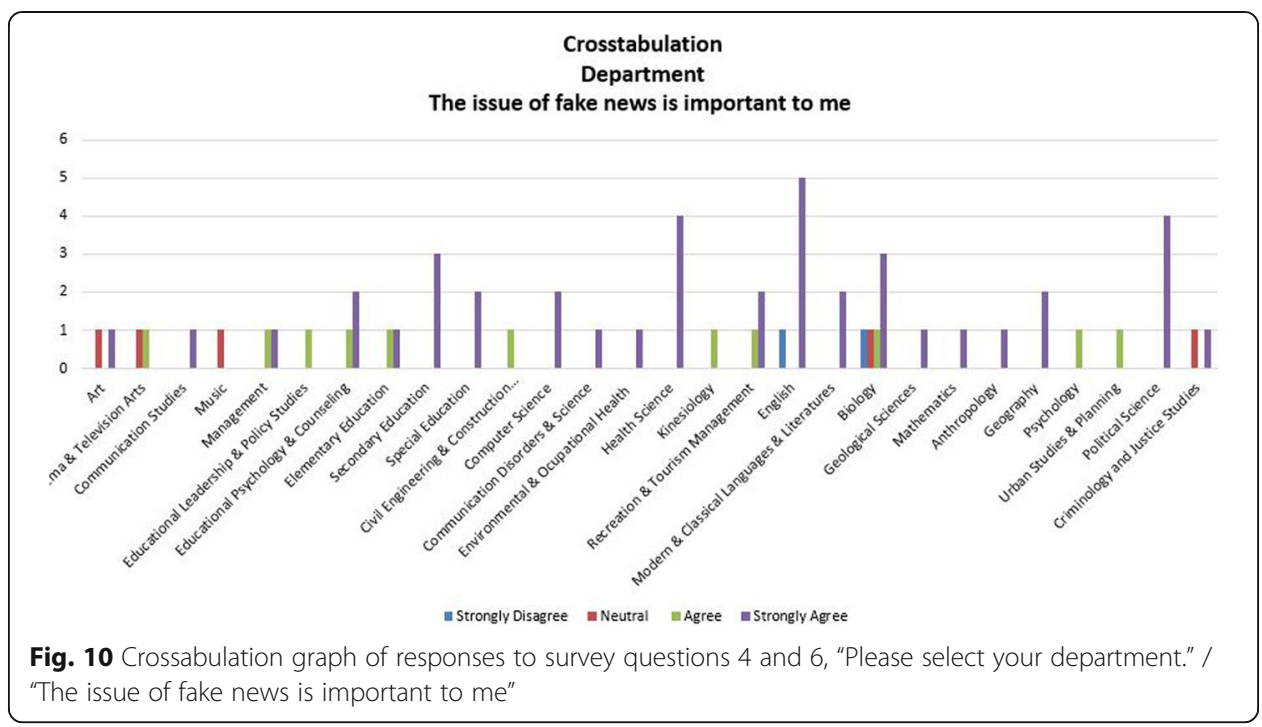

Q.9

The cross-tabulation analysis for age and question 9 (See Fig. 12) determined that all age groups other than 55-64 felt that they were not susceptible to fake news as an academic and scholar. The 55-64 age group represents $16 \%$ of our total respondents, and it is not clear why this group does feel susceptible. The highest age group of 75 years and above did not feel susceptible to fake news. As a result, we could not simply assume that more senior faculty feel more susceptible to fake news and that the phenomenon is age related. The chi-square analysis showed no statistical significance.

The cross-tabulation analysis for gender and question 9 (See Fig. 13) revealed that female faculty members considered themselves less susceptible to fake news than their male counterparts by a margin of $16 \%$ (females $75 \%$ vs males $59 \%$ ). The chi-square analysis did show a statistical significance when analyzing gender and the relationship to question 9.

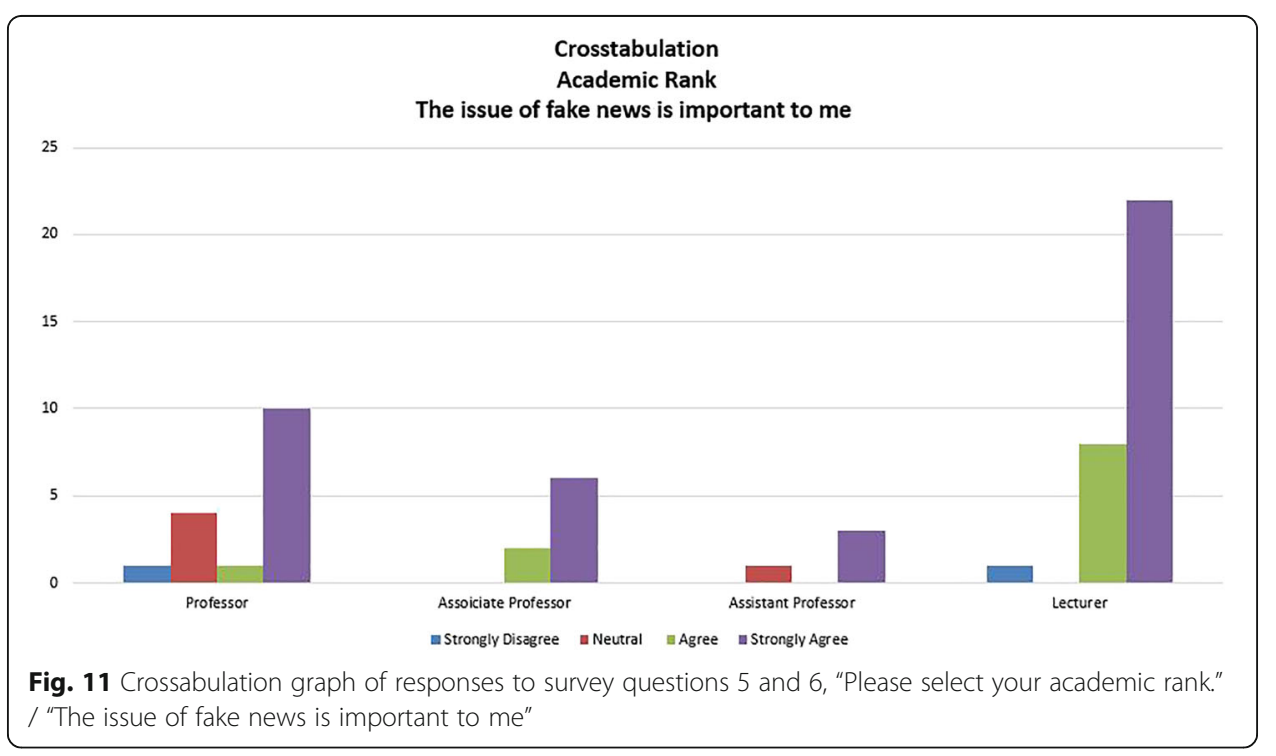




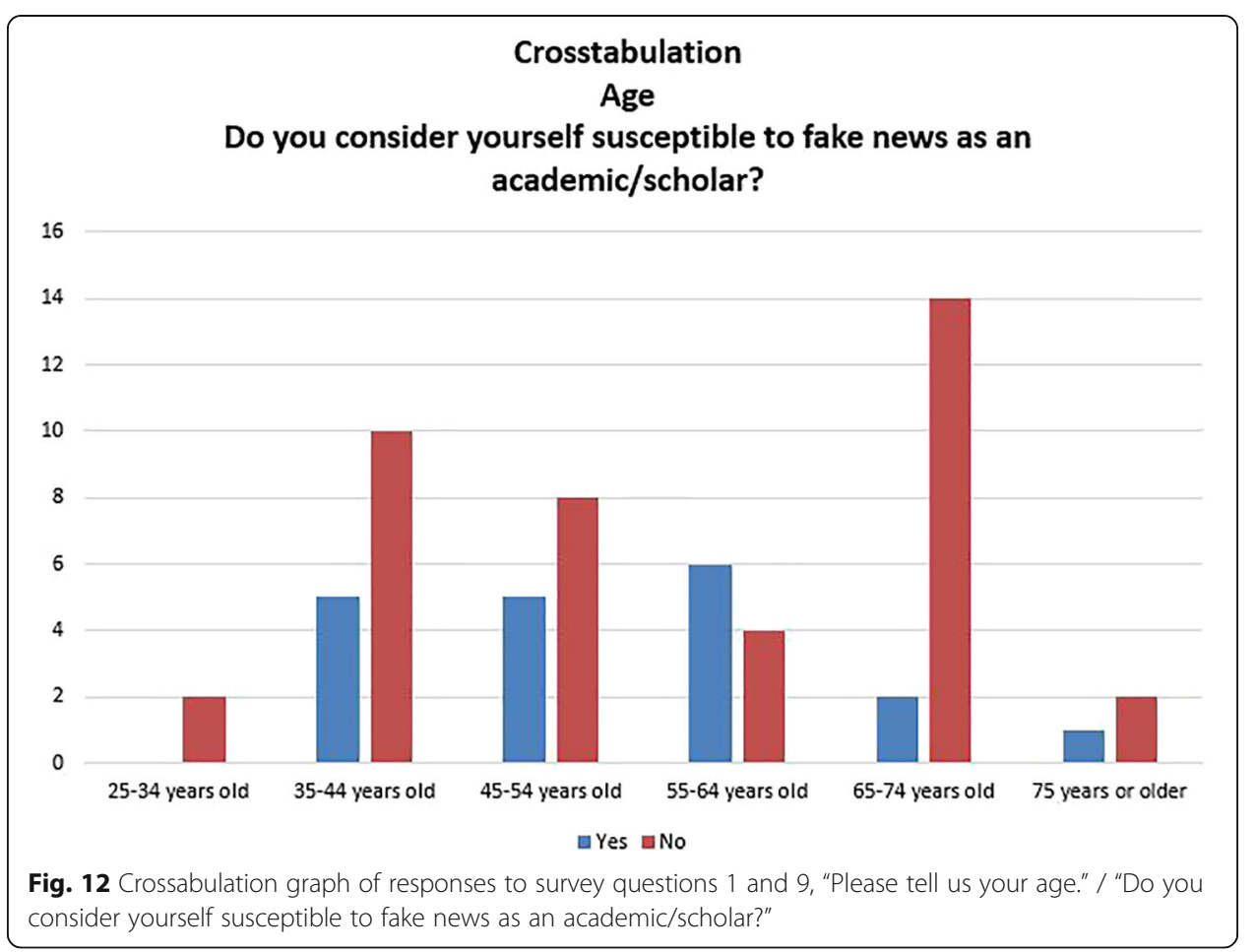

The cross-tabulation analysis for college and question 9 (See Fig. 14) determined that faculty in every college other than the College of Health and Human Development and the College of Business and Economics reported that they did not feel susceptible to fake news. An equal number of faculty from the College of Health

\section{Crosstabulation \\ Gender Identity \\ Do you consider yourself susceptible to fake news as an academic/scholar?}

30

25

20

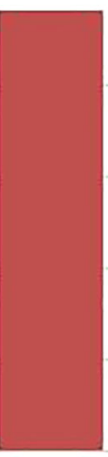

Female

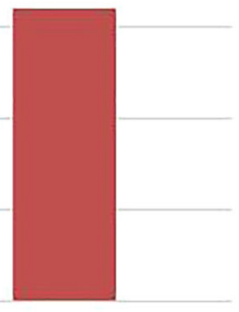

0
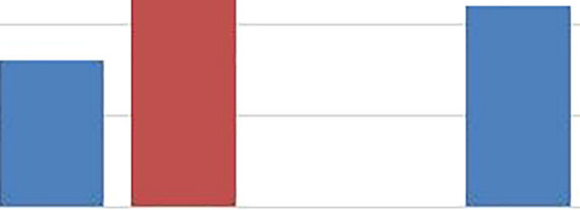

Male

ares a No

Fig. 13 Crossabulation graph of responses survey questions 2 and 9, "What is your gender identity?" / "Do you consider yourself susceptible to fake news as an academic/scholar?" 
and Human Development and the College of Business and Economics reported they were and were not susceptible to fake news. The chi-square analysis showed no statistical significance.

The cross-tabulation analysis for departments and question 9 was too granular and yielded little insight. The chi-square analysis showed no statistical significance.

The cross-tabulation analysis for rank and question 9 (See Fig. 15) determined that the majority of faculty from all ranks felt that they were not susceptible to fake news. However, the minority was not insignificant. Thirty-two percent of respondents reported that they felt susceptible to fake news. The chi-square analysis showed no statistical significance.

\section{Q.11}

A cross-tabulation or chi-square analysis was not possible, as question 11 allowed respondents to select multiple responses. Therefore the only analysis that could be conducted was a frequency distribution of where respondents encountered fake news most frequently. For this question nearly all faculty (93.22\%) reported encountering fake news through social media. Oral communication (59.32\%) and television (54.24\%) were reported as the second and third most frequent places.

\section{Discussion}

The following section will examine the qualitative (q.7, q.8) and quantitative (q. 6, q. 9, q. 11) responses separately. When analyzing the results, not all the departments and colleges were represented, and this must be taken into account. Moreover, it is important to note that many of the departments and colleges that were represented may have had only one or two respondents in total.

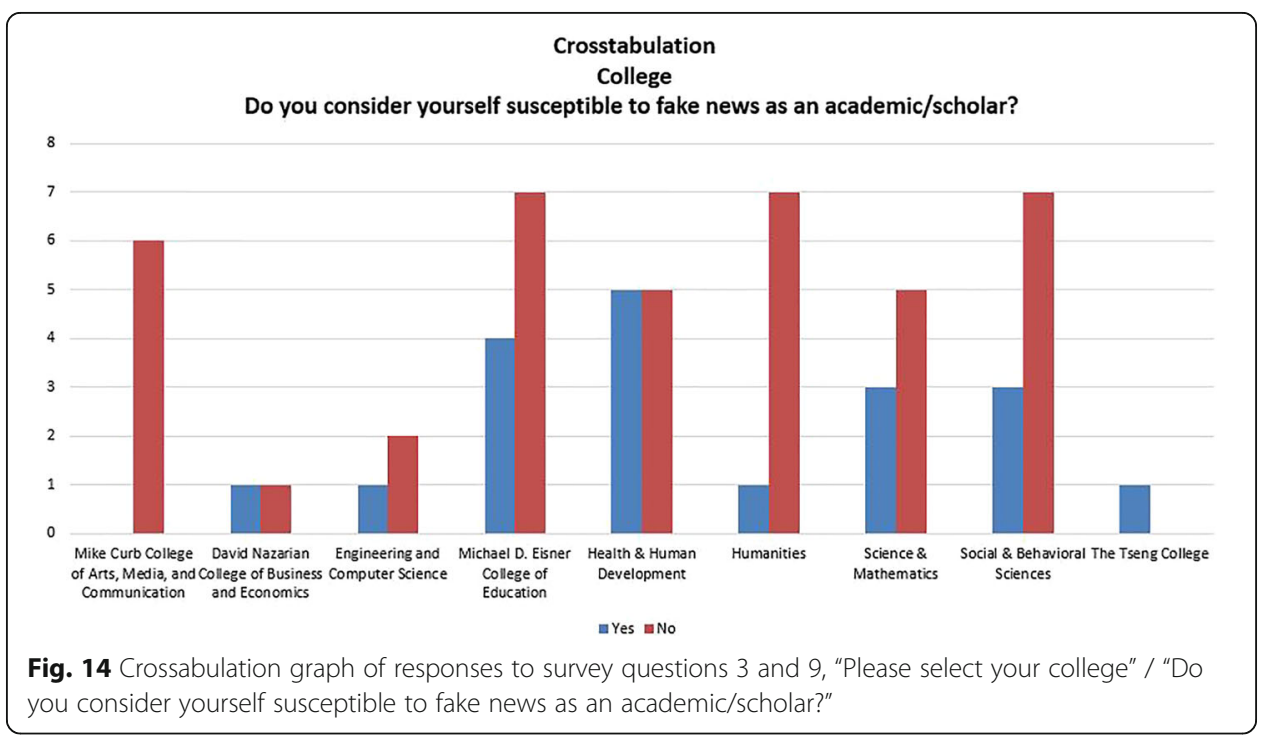




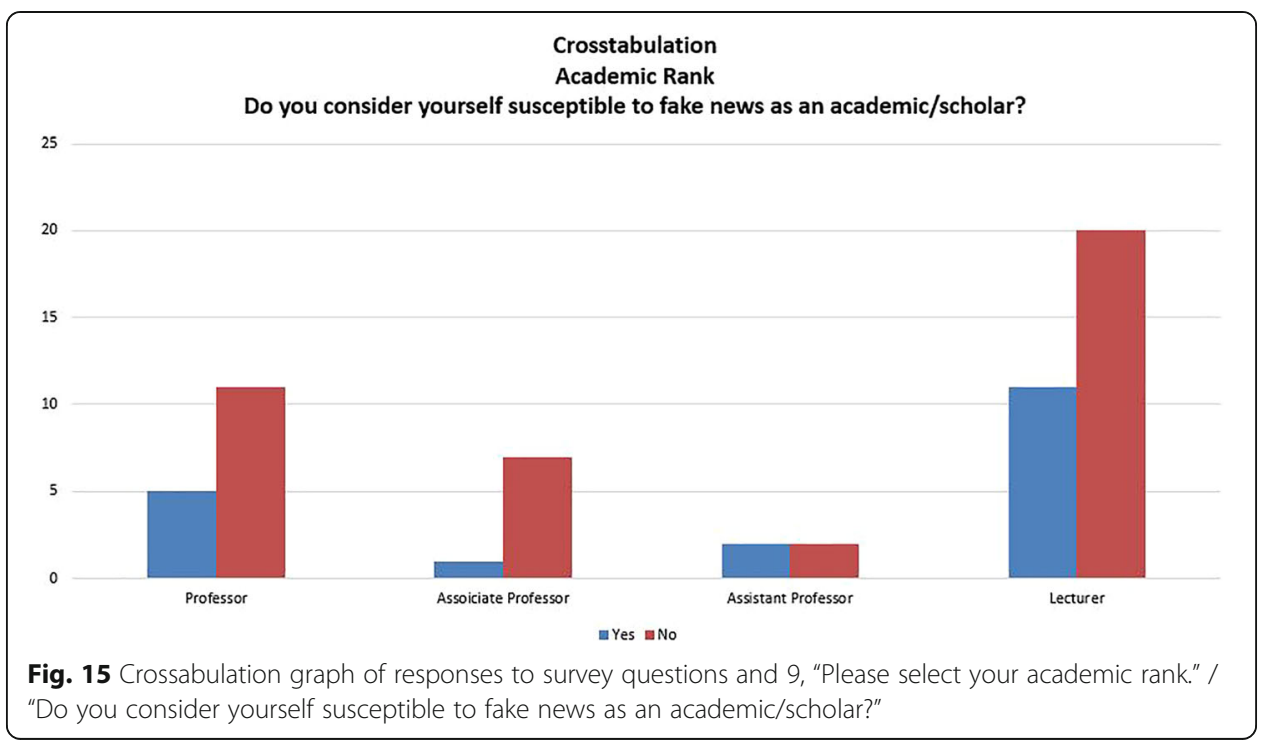

\section{Analysis of qualitative responses}

Although we surveyed faculty from one institution, it is important to note that faculty from the various departments and colleges seem to have differing views on how information is used, what makes an informed reader, and how to verify resources. This could be the result of a variety of different factors, such as what these disciplines prioritize, assumptions about information within the discipline, specific theoretical frameworks, trends in the discipline, movement towards multidisciplinary studies, and the breakdown in traditional genre and form as well as the introduction of multimedia.

Part of the reason for the differences we are seeing between the colleges for question seven and eight, it could be suggested, is that faculty definitions of fake news and the strategies to verify information are bound by discipline-specific norms. However, although fake news needs to be understood from multiple perspectives, it must be seen as a combination of currently existing definitions, ranging from misinformation, disinformation, satire and parody, and so on. Certain disciplines may be focusing on problems that are specific to their theoretical frameworks that do not fully explain the issues of fake news, and these discipline-specific definitions may exclude a more holistic but necessary view of fake news. There also may be difficulties in defining fake news in disciplines that are merging or forming new areas of study, especially in the areas that incorporate newly developed multimedia and multidisciplinary approaches.

When defining fake news and verifying information, distinctions in faculty attitudes and behavior become apparent. For example, faculty in Political Science focus on the actors and the power structures that perpetuate fake news, whereas English faculty appear to focus more on the users or readers and the motivations behind creating fake news. Faculty in Biology, however, were most concerned with the users, like those in English, and faculty in Health Sciences were concerned with the means of how information was disseminated and the message or content within it.

For faculty in the College of Education, the lack of concern with the audience for fake news may be because the discipline relies on how the instructors develop and deliver the content; possibly, the audience is seen as passive consumers and the instructor is 
the sage on the stage. It would have been interesting to learn how specific departments within the College of Education would view this issue.

Within the College of Arts, Media, and Communication, respondents were focused on the audience, which is surprising for a discipline where we expected a larger focus on the creators and the method of dissemination, especially in a college with departments that focus on expression. It is possible that faculty in this college value the role and responsibility of the audience and its agency in the reception of news or content.

It was interesting to note that the College of Education emphasized in depth research as a primary means for determining fake news. This is encouraging as these faculty are primarily responsible for teaching students who will go on to become educators.

The College of Humanities emphasized the types of sources and their origins far more than in depth research. This may be a reflection of how some disciplines within the humanities approach their own problem-solving and analysis. For example, English and History tend to be heavily text-oriented, with emphasis on the reputation of the vehicle by which information is communicated (e.g., monographs). The type of source (e.g., monograph, tweet, Wikipedia entry) is often perceived as carrying reputation or signaling value to the user.

When examining the results from faculty members, there were sharp differences in the responses to question seven and eight based on rank. The sharpest difference was noticed between lecturers and tenure-track faculty. Lecturers provided the most comprehensive definitions of fake news, as their responses touched upon all of the coding categories we developed and applied. This may stem from the fact that lectures teach the bulk of lower-level undergraduate courses at CSUN. Lecturers may more frequently come in contact with students that are likely to grapple with the issue of fake news, and, therefore, may need to be better prepared for the topic as they may discuss this issue more frequently in their courses. Furthermore, since many of the students would be in their first year, they may be more likely to inadvertently use questionable sources due to their general unawareness and inexperience.

Lecturers were also the only group to heavily emphasize in-depth research to vet resources. This is a positive sign as lecturers teach the majority of lower-level and general education courses. Lecturers deal with assignments that require students to learn how to vet information. They also work with students from a variety of disciplines. This difference may also be the result of lecturers focusing on teaching when responding to this question, while tenure-track faculty may, in contrast, be thinking of their own research. Furthermore, tenure-track faculty may see the issue of fake news as less essential, and may believe the topic should be dealt with in lower-level courses. The researchers also wondered whether assumptions of professional reputation and prestige may have impacted how tenure-track faculty responded to this question. In other words, were tenure-track faculty more hesitant or reluctant to admit having to use in depth research or fact- checking to verify fake news?

\section{Analysis of quantitative responses}

For question six no significant difference was evident when analysing the importance of fake news by age, gender, rank, or discipline. Across the spectrum, the issue of fake news was of concern to nearly all faculty (88\%), suggesting that fake news is a pervasive 
issue in higher education impacting everyone regardless of demographics, rank and discipline. For example, younger faculty may see themselves within a generation that should be able to quickly identify fake news. Similarly, senior faculty may see the need to prioritize being vigilant as they may not consider themselves digital natives. This example demonstrates that faculty may prioritize the importance of fake news for different reasons, but, nevertheless, they all still find the issue important.

Question nine asked respondents to consider whether they felt susceptible to fake news as academics or scholars. Some results seemed not to yield much insight. Age seemed to have no statistical significance, nor did college, department, or rank. Indeed, department was too narrow to derive any satisfactory conclusions from this survey, and college differences are too variable to pinpoint where or why attitudes about fake news arise.

A few of the results surprised us, however. The fact that $32 \%$ of all respondents, regardless of their ranks, felt susceptible to fake news may be an interesting avenue to pursue. Perhaps examining education levels among a population at large would provide fruitful insight. As it is, a highly educated workforce may, indeed, already feel somewhat immune to the effects of fake news. It would be interesting to see comparisons between education levels such as high school, some college, undergraduate, and graduate. The statistically significant difference between men and women in this survey was also striking and somewhat unexpected. For some reason, females were more likely to feel less susceptible to fake news than men by a margin of $16 \%$. While we are not sure of the cause, it is worth noting and may need a follow-up study focusing purely on gender differences towards fake news.

For question 11, a cross-tabulation and chi-square analysis was not possible. However, it is clear that the majority of participants in our survey viewed social media as the primary vehicle for fake news. This perspective reflects both the popular and scholarly view on the matter. Yet, what we do not have insight into to is why our participants believe social media has such an impact. We suspect that faculty likely see social media as a tool by which one can more easily manipulate and influence people in negative ways. Whether it be an intended or unintended consequence, it appears that technological manipulation has clearly impacted the way people view the reliability and availability of information on social media platforms and the ability of the public to decipher what is accurate.

\section{Implications for higher education}

As noted in the literature review, not much is currently in publication about the attitudes of university faculty on fake news. The definition of fake news itself is not standardized and is conceptualized differently by the various disciplines, resulting in a hodge-podge of approaches and understandings. For example, faculty define fake news in different ways and demonstrate distinct differences in how they determine it, based on their rank. Perhaps, it is a matter of specialization in that lecturers are expected to teach lower-level, more generalist courses, and tenure-track faculty teach the higherlevel, more specialist courses.

We find that faculty attitudes toward fake news generally fall within the more negative sub-topics of misinformation, propaganda, and rumor, but not at all in terms of 
parody, satire, and the more obscure kayfabe, which we believe are essential aspects to the concept of fake news. Perhaps the idea of fake news as parody (e.g., The Onion, the Daily Show, or SNL) for the survey respondents was too frivolous or insubstantial and not worthy of mention. Yet, the concepts of mimicry, imitation, and parody play fundamental roles in how fake news itself is generated, how it is spread, further perpetuated, and how it may be counteracted.

We believe that the results demonstrate an unclear and incomplete view of fake news among faculty. The evidence is essentially telling us that a unified or more cohesive theory of fake news may need to be developed to better study its effects. Some of the faculty we surveyed define fake news in incomplete ways, perhaps taking it as the result of poorly educated users, or of malicious actors, but not as a unified and intertwined series of complex phenomena.

There are several real-world implications for this lack of a uniform definition, especially as it relates to how faculty teach critical thinking skills. First, depending on the professors they have, students may graduate with wildly differing ideas about what constitutes fake news. Second, as budding users of complex information, they may be more easily fooled if unarmed without an all-encompassing approach to counteract fake news. Third, the fight to combat the effects of fake news will be very difficult without a wider and more comprehensive approach to and definition of the concept, especially since it can come in so many different forms and can have many different intentions. This requires students to be more vigilant in their use of information.

Finally, with regard to lecturers it was promising to see that they emphasize a variety of techniques to vet potentially fake news, making their role in teaching critical thinking skills especially important. However, students spend the majority of their time in discipline-specific courses, not general education courses, where faculty hold disparate views of what constitutes fake news and how to address it. This could be viewed as troublesome if the aim of higher education is to impart critical thinking skills "that transfer across academic domains" (Halpern 1999, p. 70). In other words, a more comprehensive concept of fake news may need to be developed and integrated into higher education pedagogy to work across all disciplines to address this gap in teaching critical thinking.

\section{Limitations}

The researchers acknowledge that there were limitations to the study. First, the researchers focused primarily on one Master's university (M1) in California, which would affect how representative the sample is for other institutions of higher education. Second, the study may not fully capture the range of ideas and interpretations of fake news among respondents. Third, this study was impacted by the minimal amount of literature on how faculty address the issue of fake news in the classroom. Fourth, survey participants were also self-reporting their reactions to and ideas about fake news. Lastly, researcher bias may have had an impact on the development of the coding and the decisions about how to organize the data.

\section{Future directions}

This paper has examined only the questions focusing primarily on how faculty define fake news, where they encounter it, and how they come to determine whether 
something is fake. Future directions for this research will include a focus on how faculty address fake news with students in their classrooms, how faculty perceive the library's role in combating fake news, and an overview and meta-analysis of the remaining survey questions.

We also believe that we could examine specific disciplines in more detail. A wider sample, perhaps at other institutions in higher education, might yield more fruitful results. Direct observations, focus groups, and other primary evidence gathering techniques might also help to supplement our original data. We also intend to examine other disciplines in detail with larger populations to see if discipline-specific norms impact how fake news is perceived.

\section{Conclusion}

In conclusion, the results suggest that faculty members at California State University, Northridge have widely divergent views and definitions of fake news. Across disciplines, ranks, ages and gender, the views seem to show little consensus. This lack of a consistent view is concerning and may have future implications for students in the areas of pedagogy and critical thinking. Therefore, it may be necessary to develop a more consistent definition and approach to the topic of fake news, if a primary goal of higher education is to create a responsible and informed citizenry.

\section{Appendix 1}

\section{Survey Questions}

\section{Demographics}

1. Please tell us your age

2. What is your gender identity?

3. Please select your college.

4. Please select your department.

5. Please select your academic rank.

\section{Personal Views}

6. The issue of fake news is important to me.

7. What is your definition of the term 'fake news'?

8. How do you determine that something is fake news?

9. Do you consider yourself susceptible to fake news as an academic/scholar?

10. How do you go about vetting information to determine its credibility?

11. Where do you typically encounter fake news?

12. Where do your students typically encounter fake news?

13. How often do you encounter fake news in your work?

\section{In the Classroom}

14. Is the topic of fake news important to students?

15. Do you address the topic of fake news in your classes?

16. How do you address the topic of fake news in your classes?

17. How often do you think your students encounter fake news?

18. How often are students using fake news in your classes?

19. Are certain students more susceptible to fake news and why?

20. Where do think your students typically encounter fake news? 
21. Do you teach students to vet information to determine credibility?

22. What tools and resources do you use to teach your students about fake news?

\section{The Role of the Library}

23. Do you use the Oviatt Library's resources/services to teach or inform your students about fake news?

24. Do you collaborate with librarians to teach or inform your students about fake news?

25. Do you feel the Oviatt Library has reputable trustworthy sources?

26. Do you feel librarians offer sufficient support related to fake news?

27. Do you feel the Oviatt Library offers sufficient support related to fake news?

28. Please share any suggestions about how the library could improve and or expand services, tools or resources on fake news.

\section{Appendix 2}

\section{Qualitative Coding Guide}

Q7. What is your definition of the term 'fake news'?

Definitions of fake news were classified using the following codes:

- 'Actors'

$\bigcirc$ News or Media (i.e., as the agent that creates the fake news)

$\bigcirc$ 'Idiots' [i.e. the uninformed but vocal and unsophisticated opinionator]

$\bigcirc$ Writer or Journalist

$\bigcirc$ Political Faction (e.g., political party, pundit, or spinner)

- 'Acted upon'

$\bigcirc$ Audience (i.e., reader, viewer, listener, people)

$\bigcirc$ Informed information consumers

$\bigcirc$ Uninformed information consumers

- 'Means or method of dissemination'

Social Media

$\bigcirc$ Journalism/News (news as the distributor of fake news)

$\bigcirc$ Radio and television broadcasts

$\bigcirc$ Print media (i.e. books, magazines)

- 'Content type'

$\bigcirc$ Propaganda

$\bigcirc$ Unverified information

$\bigcirc$ Untrue, falsified or misleading statements (i.e. misinformation and disinformation)

Biased slants or presentations

$\bigcirc$ Opinion, hearsay, or rumor

- 'Motivation or purpose'

Deception

Misinform or disinform

$\bigcirc$ Manipulate opinion

$\bigcirc$ Discredit (e.g., alternative facts, scapegoat method)

$\bigcirc$ Parody / satire / 'kayfabe' (a.k.a. make-believe)

Q8. How do you determine that something is fake news?

The actions described to vet information were classified using the following codes: 
- 'Intuition'

$\bigcirc$ Gut feeling

$\bigcirc$ Instinct

- 'Source or origin of story'

$\bigcirc$ Checking a specific news outlet

$\bigcirc$ Checking a specific author or journalist

- 'Fact Checking'

$\bigcirc$ Reviewing citations,

$\bigcirc$ Undertaking bibliographic practices

- 'Triangulation'

Comparison of multiple resources

- 'In-depth research'

Analysis and interpretation of scholarly research findings

Empirical research on a particular topic

- Non-answers (responses that fail to address the question):

$\bigcirc$ 'Do not know'

$\bigcirc$ 'It is difficult/hard' to determine

$\bigcirc$ 'It's biased'

O 'Not impartial'

Non-replies / skipped

Abbreviation

CSUN: California State University, Northridge

Acknowledgements

None.

Authors' contributions

Equal distribution of writing, analysis, data development among all authors. All authors read and approved the final manuscript.

\section{Funding}

There are no sources of funding for the research to be declared. Outside funding bodies had no role in the design of this study, the collection, analysis, and interpretation of the data, or in the writing of this manuscript.

\section{Availability of data and materials}

Authors intend to release the data from the study, comprising the whole of the anonymized responses to their survey, by posting in the CSU Northridge institutional repository ScholarWorks (url: http://scholarworks.csun.edu/), upon the completion of their use of the data. As this is ongoing and the authors intend to publish several more papers based on this data, the release date has yet to be determined.

\section{Competing interests}

The authors declare that they have no competing interests.

Received: 31 July 2019 Accepted: 4 December 2019

Published online: 03 February 2020

\section{References}

Allcott H, Gentzkow M (2017) Social media and fake news in the 2016 election. J Econ Perspect 31(2):211-236 Retrieved from https://pubs.aeaweb.org/doi/pdfplus/10.1257/jep.31.2.211

Allegretti CL, Frederick JN (1995) A model for thinking critically about ethical issues. Teach Psychol 22:46-48 https://doi.org/ 10.1207/s15328023top2201_14

American Library Association (2019) Hate speech and hate crime - advocacy. Legislation \& Issues, American Library Association Retrieved from http://www.ala.org/advocacy/intfreedom/hate

Balmas M (2014) When fake news becomes real: combined exposure to multiple news sources and political attitudes of inefficacy, alienation, and cynicism. Commun Res 41(3):430-454 https://doi.org/10.1177/0093650212453600

Batchelor $O$ (2017) Getting out the truth: The role of libraries in the fight against fake news. Reference Services Review 45(2): $143-148$

Behar-Horenstein LS, Niu L (2011) Teaching critical thinking skills in higher education: a review of the literature. J Coll Teach Learn 8:25-42 Retrieved from https://clutejournals.com/index.php/TLC 
Berger PL, Luckmann T (1966) The social construction of reality: a treatise in the sociology of knowledge. Doubleday, New York

Blair A (2010) Too Much to Know: Managing Scholarly Information Before the Modern Age. New Haven [Conn.]: Yale University Press

Blassnig S, Büchel F, Ernst N, Engesser S (2018) Populism and Informal Fallacies: An Analysis of Right-Wing Populist Rhetoric in Election Campaigns. Argumentation 1-30

Brennen B (2017) Making Sense of Lies, Deceptive Propaganda, and Fake News. Journal of Media Ethics 32(3):179-181 https://doi.org/10.1080/23736992.2017.1331023

Chatman EA (1996) The impoverished life-world of outsiders. Journal of the American Society for information science 47, $193-206$

Clarke D (2017) Developing a Metadata Community Response to the Post-Truth Information Age. DCMI International Conference on Dublin Core and Metadata applications.

Cooke NA (2017) Posttruth, truthiness, and alternative facts: information behavior and critical information consumption for a new age. Libr Q 87:211-221 https://doi.org/10.1086/692298

Cooke NA (2018) Fake news and alternative facts: Information literacy in a post-truth era. Chicago: ALA Editions.

Davies M, Barnett R (2015) The palgrave handbook of critical thinking in higher education. Springer, New York

Egan A (2019) Confidence in critical thinking: Developing learners in higher education. New York, NY: Routledge

El-Rayess M, Chebl C, Mhanna J, Hage RM (2018) Fake news judgement: The case of undergraduate students at Notre Dame University-Louaize, Lebanon, Reference Services Review, Vol. 46 Issue: 1, pp. 146-149 https://doi.org/10.1108/ RSR-07-2017-0027

Ennis RH (1989) Critical thinking and subject specificity: Clarification and needed research. Educational Researcher 18(3), 4-10 https://doi.org/10.3102/0013189X018003004

Eppler M, Mengis J (2004) The concept of information overload: A review of literature from organization science, accounting, marketing, MIS, and related disciplines. The Information Society 20(5):325-344

Fernbach PM, Light N, Scott SE, Inbar Y, Rozin P (2019) Extreme opponents of genetically modified foods know the least but think they know the most. Nature Human Behaviour 3, 251-256 https://doi.org/10.1038/s41562-018-0520-3

Good A (2017) The rising tide of educated aliteracy. The Walrus https://thewalrus.ca/the-rising-tide-of-educated-aliteracy/

Golbeck, Jennifer, Matthew Mauriello, Brooke Auxier, Keval H. Bhanushali, Christopher Bonk, Mohamed Amine Bouzaghrane, Cody Buntain et al. (2018). Fake news vs satire: A dataset and analysis. In Proceedings of the 10th ACM Conference on Web Science, pp. 17-21 https://doi.org/10.1145/3201064.3201100

Halpern DF (1999) Teaching for critical thinking: helping college students develop the skills and dispositions of a critical thinker. New Dir Teach Learn 80:69-74

Hintz WW (1940) Which propaganda? Coll Res Libraries 1(2):170-175 Retrieved from https://crl.acrl.org/index.php/cr

Irving A (1985) Study and information skills across the curriculum. London: Heinemann Educational Books

Kovach B, Rosenstiel T (2011) Blur: how to know what's true in the age of information overload. Bloomsbury, New York

Kramer RM (1999) Trust and distrust in organizations: emerging perspectives, enduring questions. Annu Rev Psychol 50(1): 569-598 Retrieved from https://pdfs.semanticscholar.org/70b9/3a3111486496db45aa5dbb81e9d6f1776a2f.pdf

Kulthau CC (1993) Seeking meaning: A process approach to library and information services. Greenwich, CT. Ablex Publ

Maxwell JA (2013) Qualitative research design: an interactive approach. SAGE, Thousand Oaks

McGivney C, Kasten K, Haugh D, DeVito JA (2017) Fake news \& information literacy: designing information literacy to empower students. Interdisciplinary Perspectives Equality Diversity 3(1):1-18 Retrieved from http://journals.hw.ac.uk/ index.php/PED/article/viewFile/46/30

McNair B (2018) Fake news: falsehood, fabrication and fantasy in journalism. Routledge, New York

Mihailidis P, Viotty S (2017) Spreadable spectacle in digital culture: civic expression, fake news, and the role of media literacies in "post-fact" society. Am Behav Sci 61(4):441-454. https://doi.org/10.1177/0002764217701217

Nahl D (2004) Measuring the affective information environment of web searchers. Proceedings of the 67th annual meeting of the American Society for Information Science and Technology, 41. Information Today, Medford

Orwell G (1946/2011) Politics and the English language. The Broadview Anthology of Expository Prose. Broadview Press, Toronto

Oxford Dictionary (2016) Post-truth. Retrieved July 15, 2019, from https://en.oxforddictionaries.com/

Palinkas LA, Horwitz SM, Green CA, Wisdom JP, Duan N, Hoagwood K (2015) Purposeful sampling for qualitative data collection and analysis in mixed method implementation research. Adm Policy Ment Health Ment Health Serv Res 42(5): 533-544. https://doi.org/10.1007/s10488-013-0528-y

Patton MQ (2002) Qualitative research and evaluation methods, 3rd edn. SAGE, Thousand Oaks

Renaud RD, Murray HG (2008) A comparison of a subject-specific and a general measure of critical thinking. Think Skills Creat 3:85-93 https://doi.org/10.1016/j.tsc.2008.03.005

Ritchie J, Lewis J, Elam G (2003) Designing and selecting samples. In: Ritchie J, Lewis J (eds) Qualitative Research Practice: A Guide for Social Science Students and Researchers, pp 77-108 Retrieved from https://mthoyibi.files.wordpress.com/2 011/10/qualitative-research-practice_a-guide-for-social-science-students-and-researchers_jane-ritchie-and-jane-lewis-eds_2 0031.pdf

Roth MS (2010) Beyond critical thinking. Chron High Educ 56:B4-B5 Retrieved from https://www.chronicle.com/

Schafer B (2018) A view from the digital trenches: lessons from year one of Hamilton 68. Alliance Securing Democracy 33:1-24 Retrieved from https:/securingdemocracy.gmfus.org/a-view-from-the-digital-trenches-lessons-from-year-one-of-hamilton-68/

Schuster SM (2007) Information literacy as a core value. Biochem Mol Biol Educ 35(5):372-373 https://doi.org/10.1002/bmb.100

Smallpage SM, Enders AM, Uscinski JE (2017) The partisan contours of conspiracy theory beliefs. Res Politics 4(4):1-7 https:// doi.org/10.1177/2053168017746554

Stodden WP, Hansen JS (2016) Politics by Kayfabe: Professional wrestling and the creation of public opinion http://static1.1. sqspcdn.com/static/f/332308/26781726/1452481855523/wrestfin.pdf?token=rq1 phFlu3\%2Bd2hD1Qnz\%2BvGVI47wU\%3D

Taylor P (2003) Munitions of the mind: a history of propaganda from the ancient world to the present era, 3rd edn. Manchester University Press, New York

Tsui L (2002) Fostering critical thinking through effective pedagogy: Evidence from four institutional case studies. Journal of Higher Education 73, 740-763 https://www.tandfonline.com/doi/abs/10.1080/00221546.2002.11777179 
Uscinski J, Parent J (2014) American conspiracy theories. Oxford; New York: Oxford University Press

Vedder A, Wachbroit R (2003) Reliability of information on the internet: some distinctions. Ethics Inf Technol 5(4):211-215 https://doi.org/10.1023/B:ETIN.0000017738.60896.77

Washington Post (2019) Fact checker: Tracking all of President Trump's false or misleading claims. Retrieved from https:// www.washingtonpost.com/graphics/politics/trump-claims-database/?utm_term=.c3f25d837837

Zipf GK (1949) Human behavior and the principle of least effort: An introduction to human ecology. Cambridge, MA: Addison-Wesley

Zurloni V, Anolli L (2010) Fallacies as Argumentative Devices in Political Debates. In Revised Selected Papers of the International Workshop on Multimodal Communication in Political Speech. Shaping Minds and Social Action - Volume 7688. Isabella Poggi, Francesca D'Errico, Laura Vincze, and Alessandro Vinciarelli (Eds.), Vol. 7688. Springer-Verlag, Berlin, Heidelberg, 245-257

Publisher's Note

Springer Nature remains neutral with regard to jurisdictional claims in published maps and institutional affiliations.

Ready to submit your research? Choose BMC and benefit from:

- fast, convenient online submission

- thorough peer review by experienced researchers in your field

- rapid publication on acceptance

- support for research data, including large and complex data types

- gold Open Access which fosters wider collaboration and increased citations

- maximum visibility for your research: over $100 \mathrm{M}$ website views per year

At $\mathrm{BMC}$, research is always in progress.

Learn more biomedcentral.com/submissions 